\title{
Multimodal Aposematic Signals and Their Emerging Role in Mate Attraction
}

\author{
Bibiana Rojas ${ }^{1 *}$, Emily Burdfield-Steel ${ }^{1}$, Chiara De Pasqual ${ }^{1+}$, Swanne Gordon ${ }^{1 \dagger}$, \\ Linda Hernández ${ }^{1 \dagger}$, Johanna Mappes ${ }^{1 \dagger}$, Ossi Nokelainen ${ }^{1 \dagger}$, Katja Rönkä ${ }^{1,2 \dagger}$ and \\ Carita Lindstedt ${ }^{1}$ \\ ${ }^{1}$ Department of Biological and Environmental Science, Centre of Excellence in Biological Interactions, University of Jyvaskyla, \\ Jyväskylä, Finland, ${ }^{2}$ Faculty of Biological and Environmental Sciences, Organismal and Evolutionary Biology Research \\ Programme, University of Helsinki, Helsinki, Finland
}

\section{OPEN ACCESS}

Edited by:

Varvara Yu. Vedenina, Institute for Information Transmission

Problems (RAS), Russia

Reviewed by:

Ximena J. Nelson,

University of Canterbury, New Zealand

Fabio Cortesi,

The University of Queensland,

Australia

${ }^{*}$ Correspondence:

Bibiana Rojas

bibiana.rojas@jyu.fi

†Authors' names in alphabetical order.

Specialty section:

This article was submitted to Behavioral and Evolutionary Ecology, a section of the journal

Frontiers in Ecology and Evolution

Received: 01 May 2018

Accepted: 13 June 2018

Published: 03 July 2018

Citation:

Rojas B, Burdfield-Steel E, De Pasqual C, Gordon S, Hernández L, Mappes J, Nokelainen O, Rönkä K and Lindstedt $C$ (2018) Multimodal

Aposematic Signals and Their Emerging Role in Mate Attraction.

Front. Ecol. Evol. 6:93.

doi: 10.3389/fevo.2018.00093
Chemically defended animals often display conspicuous color patterns that predators learn to associate with their unprofitability and subsequently avoid. Such animals (i.e., aposematic), deter predators by stimulating their visual and chemical sensory channels. Hence, aposematism is considered to be "multimodal." The evolution of warning signals (and to a lesser degree their accompanying chemical defenses) is fundamentally linked to natural selection by predators. Lately, however, increasing evidence also points to a role of sexual selection shaping warning signal evolution. One of the species in which this has been shown is the wood tiger moth, Arctia plantaginis, which we here put forward as a promising model to investigate multimodality in aposematic and sexual signaling. A. plantaginis is an aposematic diurnal moth which exhibits sexually dimorphic coloration as well as sex-limited polymorphism in part of its range. The anti-predator function of its coloration and, more recently, its chemical defenses (even when experimentally decoupled from the visual signals), has been well-demonstrated. Interestingly, recent studies have revealed differences between the two male morphs in mating success, suggesting a role of coloration in mate choice or attraction, and providing a possible explanation for its sexual dimorphism in coloration. Here, we: (1) review the lines of evidence showing the role of predation pressure and sexual selection in the evolution of multimodal aposematic signals in general, and in the wood tiger moth in particular; (2) establish gaps in current research linking sexual selection and predation as selective pressures on aposematic signals by reviewing a sample of the literature published in the last 30 years; (3) highlight the need of identifying suitable systems to address simultaneously the effect of natural and sexual selection on multimodal aposematic signals; and (4) propose directions for future research to test how aposematic signals can evolve under natural and sexual selection.

Keywords: warning coloration, multimodal signals, predator-prey interactions, sexual selection, chemical signals, signal variation 


\section{INTRODUCTION}

Animals can communicate their quality to potential mates or predators with different types of signals (Maynard Smith and Harper, 2003). Because signals may be targeted to different receivers, the multiple functions can sometimes lead to a conflict between natural and sexual selection, which imposes limitations on signal evolution. For instance, in Darwin and Fisher's sexual selection theories (Darwin, 1869; Fisher, 1930), some traits can be favored by sexual selection, such as the vivid body colors on a male guppy, Poecilia reticulata (Endler, 1988b; Figure 1A), but the evolution of these conspicuous ornaments may be constrained by the individual's survival, as they are also easier to detect by predators or parasites (Endler, 1988b; Kotiaho et al., 1998; Zuk and Kolluru, 1998; Lindström et al., 2005). Likewise, females of the Túngara frog, Engystomops pustulosus, prefer male mating calls of increased complexity which, in turn, are easier to detect and locate by bats (Ryan et al., 1982; Figure 1C); and females of the wolf spider Hygrolycosa rubrofasciata (Figure 1D) prefer males that drum their abdomen against the dry leaves at higher rates (Parri et al., 1997), which can lead to increased predation risk (Kotiaho et al., 1998). However, if different elements of the signal are targeted to a different receiver or evoke different responses, then they can evolve despite being the subject of both selective factors (Endler, 1992; Figure 1). That is the case in the dorsal and ventral markings in the wings of butterflies of the genus Bicyclus (Oliver et al., 2009), such as B. Anynana (Figure 1B). While the eyespots on the ventral side of their wings deter predators (Lyytinen et al., 2004), the UV reflection of the dorsal markings signal potential mates (Robertson and Monteiro, 2005).

One way to increase the efficacy of a particular signal is to stimulate multiple sensory modalities of the receiver simultaneously (Partan and Marler, 1999). This type of multimodal signals are used in the aposematic displays that defended organisms use to advertise their unprofitability (e.g., toxicity, unpalatability, or physical defenses such as spines) to potential predators (Poulton, 1890; Cott, 1940; Edmunds, 1974; Ruxton et al., 2004; Rojas et al., 2015b). Multimodal signals are also common in sexual communication where males can advertise their quality via multiple cues in multiple sensory channels (Bradbury and Vehrencamp, 2011). More recently, it has become evident that certain visual components, such as bright color patterns, in multimodal displays may have a dual function both as aposematic and sexual signals (Cummings and Crothers, 2013). In contrast, much less information exists on whether or not secondary defenses could also have a dual function in both chemical communication to potential predators and potential mates (Conner et al., 1981).

Here, we: (1) review the multiple lines of evidence showing both how predation pressure has shaped the evolution of multimodal aposematic signals, as well as the less studied role of sexual selection in warning color evolution; (2) establish the gaps in current studies linking sexual selection and predation as selective pressures on the warning displays of aposematic species, by reviewing a sample of the literature published over the last 30 years; (3) point out the need to identify representative model systems from different taxonomic groups where both
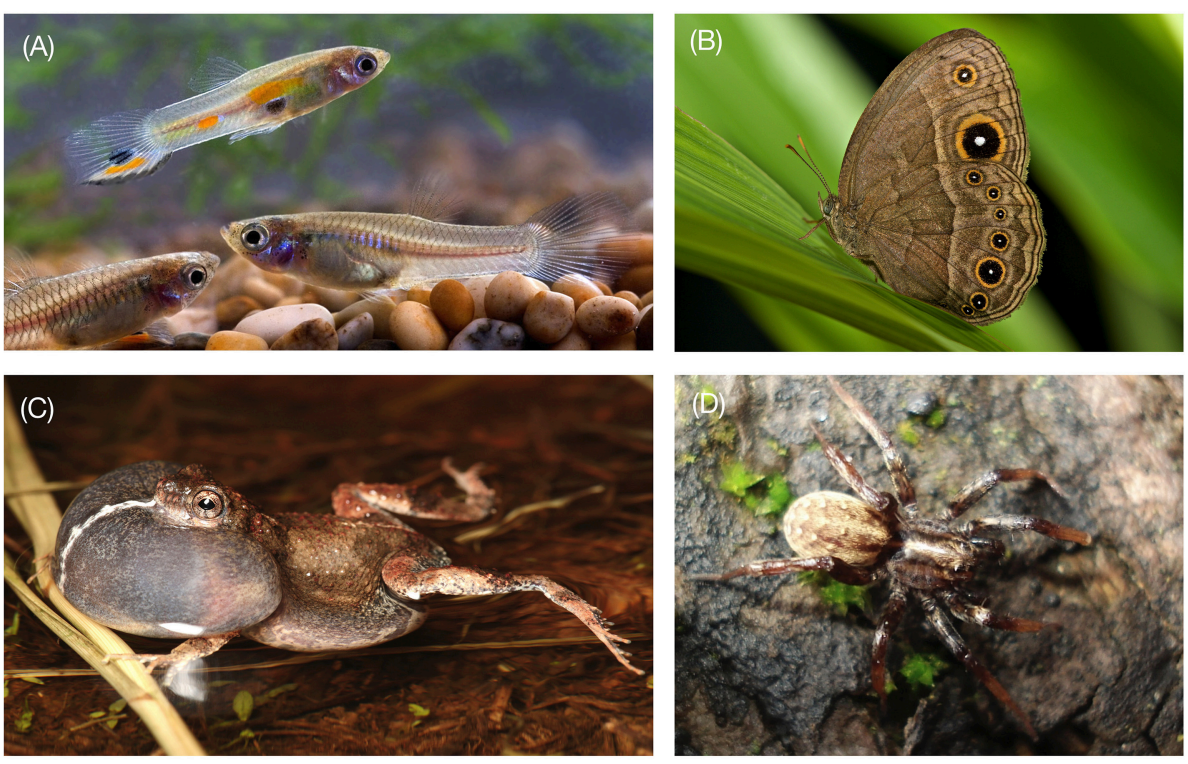

FIGURE 1 | Examples of organisms whose signals are under the influence of both sexual and natural selection. (A) Trinidadian guppy, Poecilia reticulata. Females prefer signals that are also an easier target for predators; (B) Squinting Bush-brown, Bicyclus anynana. The eyespot markings on the ventral side of their wings deter predators, while dorsal markings signal to potential mates; (C) Túngara frog, Engystomops pustulosus. Females prefer signals of higher complexity, which are also easier to detect by predators such as bats; and (D) Wolf spider Hygrolycosa rubrofasciata. Males vibrate their abdomen against the dry leaf substrate producing a drumming that is even audible for humans. Females prefer males with a high drumming rate, yet a high drumming rate can lead to increased predation risk. Photos: (A) PH Olsen CC BY 3.0, Wikimedia Commons; (B) Oskar Brattström; (C) R. Taylor; (D) Sanja565658 CC BY-SA 3.0, Wikimedia Commons. 
the function and ecological significance of coloration and compounds used in chemical communication are well-known, to understand the interplay between sexual selection and selection by predators on the different components of multimodal signals. To this end, we use the wood tiger moth A. plantaginis as a case study; and (4) suggest specific paths for future research to test how aposematic signals can be used in mating contexts, and evolve under (the interacting effects of) natural and sexual selection.

\section{APOSEMATISM IS INHERENTLY MULTIMODAL}

Animal displays often consist of several components (Bradbury and Vehrencamp, 2011). When multiple components stimulate different sensory systems in the receiver, for example the visual and the auditory (Figure 2A), these displays are considered multimodal (Partan and Marler, 1999; Higham and Hebets, 2013). If these multiple components, however, elicit receiver responses in the same sensory modality, these displays are not considered multimodal and are referred to simply as multicomponent (Partan and Marler, 2005; Bradbury and Vehrencamp, 2011; Higham and Hebets, 2013). For example, a visual signal may contain several components such as color, pattern, and size (Figure 2B), which may even provide different information to the receiver, but in the end only stimulates one sensory (visual) modality (Rowe, 1999).

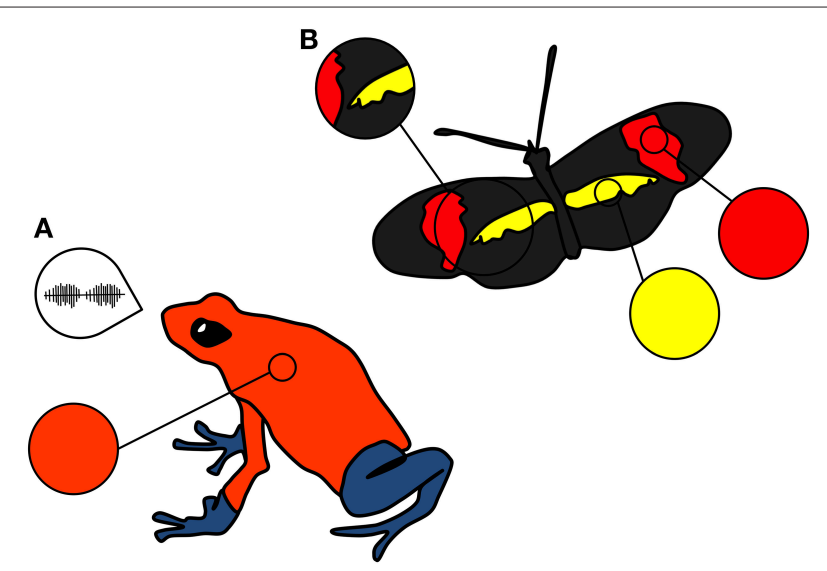

FIGURE 2 | Illustration of the difference between (A) multimodal and (B) multicomponent signals. (A) The strawberry poison frog, Oophaga pumilio, has both visual (color) and acoustic (call) signals. While both are involved in sexual selection (Maan and Cummings, 2012; Dreher and Pröhl, 2014), these stimulate different sensory (visual and auditory) channels or modes in the receiver. (B) The butterfly Heliconius erato has both color and pattern components to its visual signal (Finkbeiner et al., 2014). These may (or may not) encode different information, but stimulate the same sensory channel or mode (vision) in the receiver. Note that we are here focusing only on the visua signal of this butterfly for the purpose of illustrating multicomponency. $\mathrm{H}$. erato is also chemically defended and the combination of its secondary defences and its visual signal make up their multimodal aposematic display.
Multimodal signals are thought to improve associative learning because they provide more information per unit of time than uni-modal displays (Partan and Marler, 2005) and, thus, the interaction between multiple types of signals is often expected to be more efficient than each signal on its own. However, there are various types of multimodal signals, which differ in the type of response they elicit in the receiver, depending on whether each component acts independently, exerts dominance or modulation over the other signal(s), or give rise to an entirely new response (Partan and Marler, 1999).

With the coupling of a warning signal and a secondary (e.g., chemical) defense, aposematic organisms are capable of deterring predators by stimulating, for example, their visual and olfactory/gustatory (chemical) sensory channels. Therefore, aposematism is inherently multimodal (Rowe and Guilford, 1999; Rowe and Halpin, 2013). The most common primary defense in warning displays is warning coloration (visual component). To ensure its efficacy as a signal, warning coloration is expected to be conspicuous and distinctive, and therefore easy to learn and memorize, as all these characteristics facilitate predator's associative learning (Cott, 1940). In fact, predators seem to remember the association between aposematic signals and unprofitability for longer than when learned for unprofitable cryptic species (Roper and Redston, 1987; Roper, 1994). Red, orange, and yellow have been suggested to be efficient warning signals given their color constancy under varied light environments, and their high contrast against different backgrounds (Stevens and Ruxton, 2012; Figure 3). Likewise, color patterns with high internal contrast, such as black and white or black and yellow, have been proven to be learned faster (Zylinski and Osorio, 2013).

In addition to visual signals, sounds such as the buzz of bumblebees (Siddall and Marples, 2011) or the ultrasonic clicks of some tiger moth species (Dunning and Kruger, 1995; Hristov and Conner, 2005; Ratcliffe and Nydam, 2008) have shown to protect defended prey from predators such as birds and bats, respectively. Likewise, skunks use warning sounds and behaviors to advertise the possession of chemical defenses, which they only spray if absolutely necessary (Andersen et al., 1982; Lartviere and Messier, 1996). Interestingly, although not conducted with the purpose of studying warning displays, a study by Tuttle and Ryan (1981) showed that the frog-eating bat, Trachops cirrhosus, is capable of distinguishing edible from unpalatable frogs on the basis of their mating calls (Tuttle and Ryan, 1981), hinting at a prominent role of warning signals of different sensory modalities in the deterrence of non-visually-oriented predators.

Among secondary defenses, the most prominent are defensive chemicals. Examples of chemical defenses in vertebrates include the alkaloids found in poison frogs (Saporito et al., 2012; Santos et al., 2016), the tetrodotoxins found in some newts, pufferfish and some harlequin toads (Mosher et al., 1964; Kim et al., 1975), and the disulfides (among other compounds) sprayed by skunks (Andersen et al., 1982). Among invertebrates, some common defensive compounds are the iridoid glycosides (Lindstedt et al., 2010; Reudler et al., 2015), cardenolides, pyrrolizidine alkaloids, pyrazines, and cyanide compounds found in numerous insects (Rothschild et al., 1979, 1984; Bowers, 1992), as well as the 

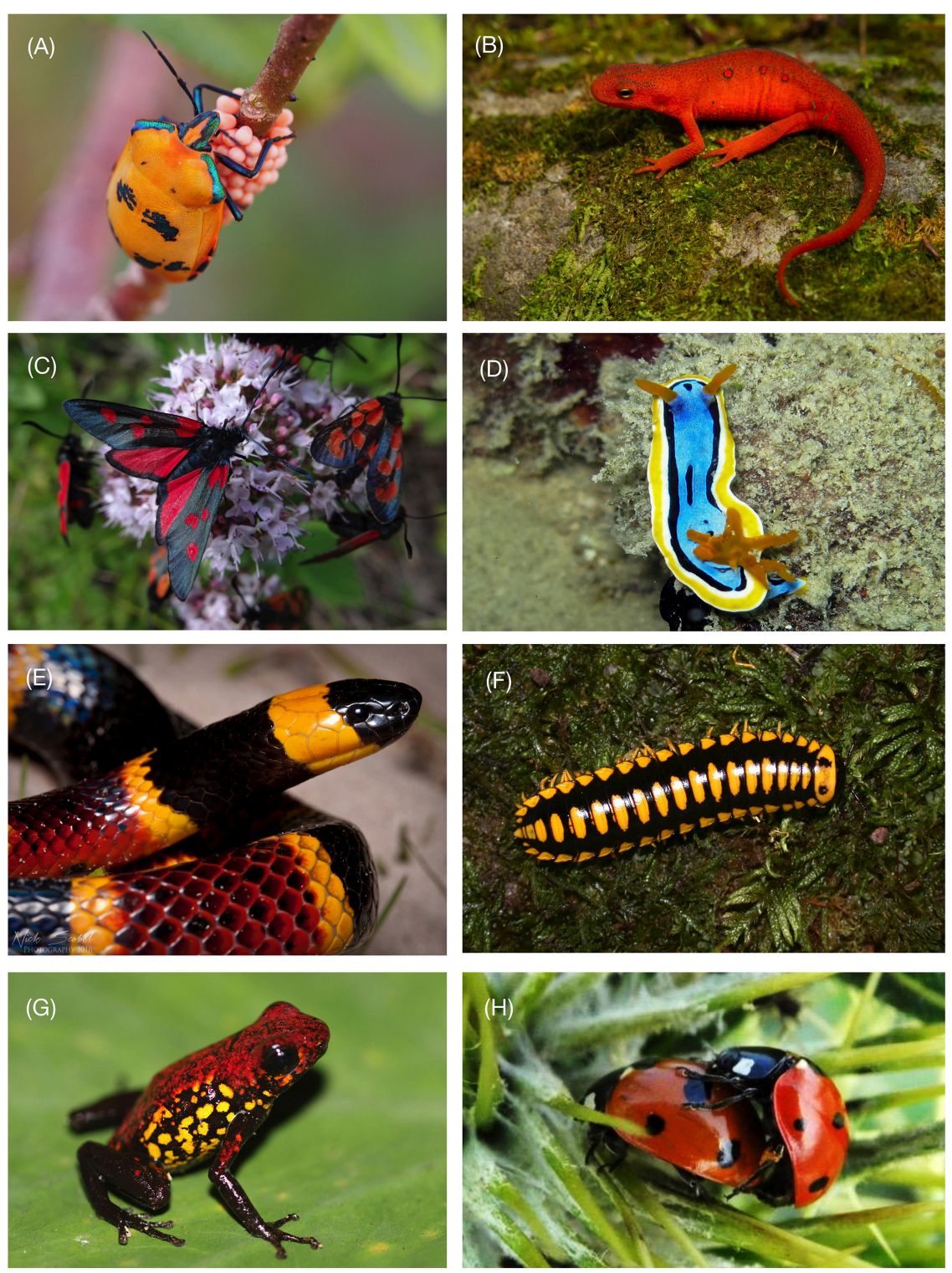

FIGURE 3 | Aposematism is widespread across the animal kingdom. (A) Harlequin bug, Tectocoris diophthalmus; (B) Eastern newt (eft form), Notophtalmus viridescens; (C) Burnet moths, Family Zygaenidae; (D) Sea slug, Chomodoris annae; (E) Eastern coral snake, Micrurus fluvius; (F) Appalachian mountains millipede, Apheloria polychroma; (G) Harlequin poison frog, Oophaga occultator; (H) ladybird, family Coccinelidae. Photos: (A) E. Burdfield-Steel; (B,D) JP Lawrence; (C,H) B. Rojas; (E) N. Scobel; (F) P. Marek; (G) P. Palacios.

furanosesquiterpenes and diterpenes (among others) found in nudibranch molluscs (Winters et al., 2018). These defenses may stimulate the olfactory or gustatory channels, or both.

\section{THE INTERPLAY BETWEEN NATURAL AND SEXUAL SELECTION IN SHAPING MULTIMODAL APOSEMATIC SIGNALS}

Although there is no consensus about how aposematic coloration initially evolved, it has been suggested that it may have appeared as a co-option to some form(s) of intraspecific communication (Figure 4). That is, for example, markings allowing individual recognition (Figure 4B), or sexually selected traits being modified to have a double function (to wardoff would-be predators and either indicate status, or attract potential mates) once the species had developed an effective secondary defense (Mallet and Singer, 1987). Given our focus on aposematism we will primarily discuss natural selection imposed by predation pressure for the remainder of this review.

The evolution of warning signals via natural selection may be coupled with sexual selection in both a stabilizing or diverging manner, and both forces can work together on different temporal (e.g., juvenile vs. adult life stages) or spatial 

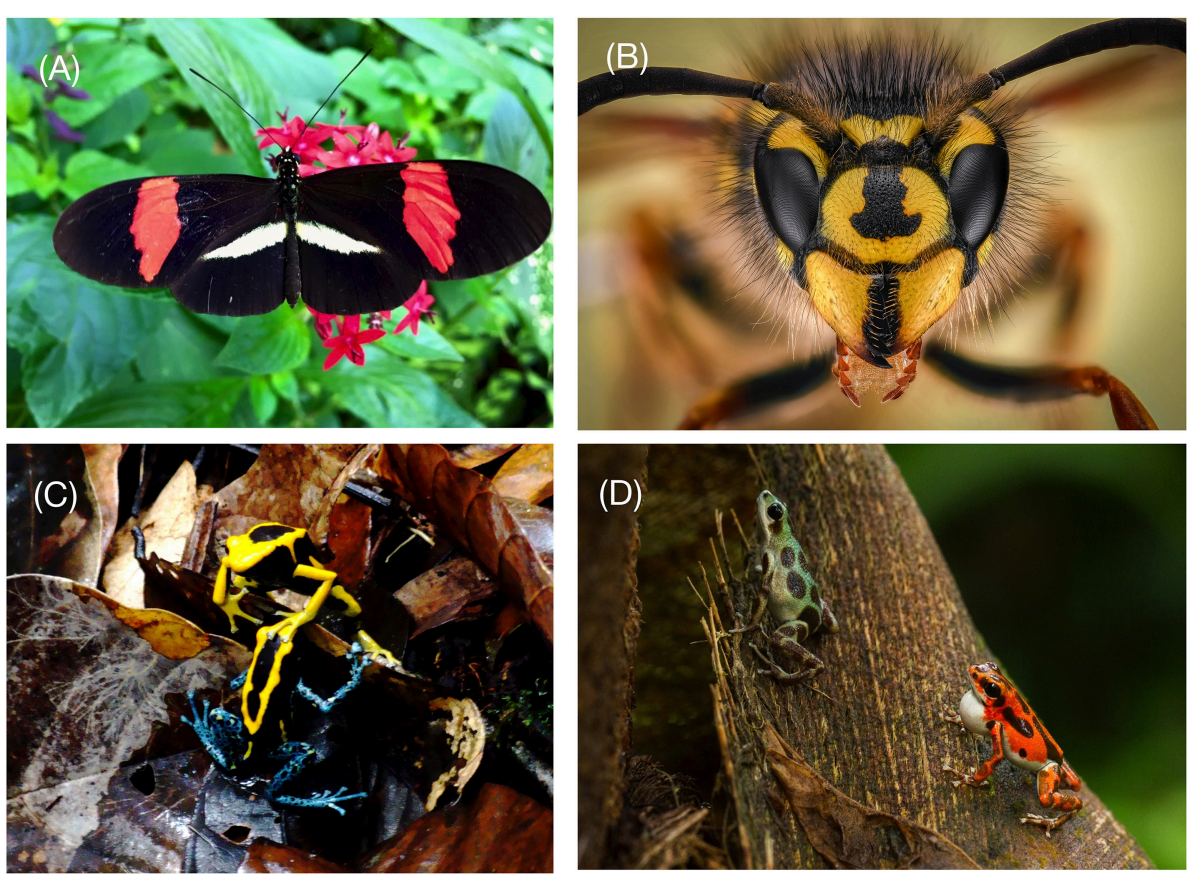

FIGURE 4 | In some aposematic species warning signals are also used for intraspecific communication. (A) In the postman butterfly, Heliconius erato, wing color pattern can serve a dual purpose in predator deterrence and mate attraction; (B) Some wasps can use their facial yellow-and-black markings for individual recognition and status signaling; (C) Males of the dyeing poison frog (Dendrobates tinctorius) tend to have yellower dorsal areas, possibly to enhance protection from predators during tadpole transport, while females with higher amounts of yellow in their frontal area are more often found in courtship; (D) In some populations of the strawberry poison frog (Oophaga pumilio), brighter males are preferred by females and also have a higher status in agonistic encounters with other males. Photos: (A) S. Finkbeiner; (B) E. Florin Niga; (C) B. Rojas; (D) A. Pašukonis.

(e.g., geographic) scales. Depending on the cognitive abilities of receivers (predators and mates) signals may be perceived differently, leading to differential selection and reaching different balances between them (Endler, 1992). An example of both forces acting at the same time can be observed in the strawberry poison frog, Oophaga pumilio, where females have been shown to prefer males with the brightest warning signal (Maan and Cummings, 2008) who, in turn, have the most noxious chemical defense (Maan and Cummings, 2012). This type of "honest signaling" of prey defenses may facilitate synergistic selection of both warning and sexual signal efficiency (Maan and Cummings, 2012; see details below) as females may benefit from mating with welldefended males.

When these dual selection pressures work in a divergent manner, sometimes they can cancel each other's effect or lead to fluctuating evolutionary responses of the warning signal depending on the selection strength of each side over time. For example, although under stabilizing selection by predators, female preference has been shown to facilitate phenotypic divergence through hybridization in harlequin poison frogs, Oophaga histrionica (Medina et al., 2013). In Neotropical longwing butterflies, genus Heliconius, two sister species $(H$. melpomene and $H$. cydno) have recently diverged to mimic different model taxa, which increases the survival benefits of both, but their mimetic coloration could lead to a cost associated to mate recognition in both species due to the time and energy spent while approaching and courting females of the co-mimic species (Jiggins et al., 2001; Estrada and Jiggins, 2008). Therefore, the multimodal nature of animal signals is prone to the evolution of complex biological interactions (Maynard Smith and Harper, 2003), yet these are seldom addressed simultaneously. In the following sections, we discuss in detail how natural and sexual selection can influence aposematic displays.

\section{The Interactive Effect of Natural and Sexual Selection Can Maintain Intra-and Inter-Population Variation in Warning Coloration}

The interplay between natural and sexual selection in the evolution of aposematic signals is particularly interesting in species in which the variability of the signal challenges the "uniformity" assumption of aposematism. Whilst a non-variable signal within a population is expected in order to favor predator avoidance learning (Endler, 1988a; Joron and Mallet, 1998; Mallet and Joron, 1999; Lindström et al., 2001; Endler and Mappes, 2004; Darst et al., 2006; Mallet, 2010; Chouteau et al., 2016), as stated above, a variable signal-without losing its conspicuous naturecould be associated with the relative attractiveness of some individuals over others (Ueno et al., 1998; Maan and Cummings, 2009). For that reason, aposematic species with a high withinpopulation phenotypic variability are excellent models to test 
how both natural and sexual selection affect the evolution and design of warning signals.

Among the extensive scientific literature regarding aposematic species, only a handful of species have been studied in terms of how warning signal diversity varies intraspecifically both within and between populations. Whilst many studies have expanded our knowledge on the shape and function of warning signals, most have focused only on the emitter end (i.e., the prey). However, to understand the complexity of warning signal variation within and between populations, it is necessary to determine what are the pressures that could be affecting the survival and reproductive success in populations, and how these warning displays act in concert to outweigh the cost of their expression (Hebets and Papaj, 2005; Gohli and Hogstedt, 2009).

One of the species in which multiple selective factors have been studied in relation to warning signal evolution, within and between populations, is the strawberry poison frog, Oophaga pumilio. Several studies have shown that the geographic variation and polymorphism in its aposematic signals is the result of the combined action of natural and sexual selection. Predators avoid warningly colored plasticine models in the field (e.g., Saporito et al., 2007; Hegna et al., 2011), and controlled experiments in the laboratory have shown that not only do females prefer to mate assortatively with males of their own morph [Summers et al., 1999; Reynolds and Fitzpatrick, 2007; Maan and Cummings, 2008; but see Yang et al. (2016) for a study showing that assortative mating occurs in allopatric populations but not in sympatric ones], but also prefer overall males with brighter coloration (Maan and Cummings, 2009). However, calls (acoustic signals) seem to be more important than coloration for female choice (Dreher and Pröhl, 2014). Males hold territories that are defended from other males through calls, and calling activity and perch height, a proxy for exposure, are correlated with mating success (Pröhl and Hödl, 1999). Only the most conspicuous males can afford to use the more exposed calling sites (Rudh et al., 2011), as they are presumably better protected from predators. More conspicuous or brighter males are also bolder (Rudh et al., 2013) and more aggressive (Crothers et al., 2011; Crothers and Cummings, 2015), suggesting that aposematic signals in this species have also been co-opted as an indicator of fighting abilities (Crothers and Cummings, 2015).

In the dyeing poison frog, Dendrobates tinctorius, an interplay between natural and sexual selection affecting warning signals has also been proposed, although in lesser detail. Field studies with frog models at Nouragues Reserve (French Guiana) have shown that the warning signals of $D$. tinctorius elicit few avian predator attacks (Noonan and Comeault, 2009; Rojas et al., 2014) and are subject, as expected, to positive frequencydependent selection (Comeault and Noonan, 2011). Males of this population have a higher proportion of yellow in their dorsal area than females, and the authors suggest that a synergy between sexual selection (in the form of parental care) and aposematism could select for yellower males (Rojas and Endler, 2013). Females, in contrast, seem to be favored by sexual selection when they present a higher amount of yellow in their frontal area, which is highly visible during courtship interactions (Rojas, 2012). Pairs in this population show no signs of assortative mating for color patterns, which could help explain the high phenotypic variation observed (Rojas, 2012).

As with vertebrates, studies aiming to explain warning color polymorphism within populations of arthropods are mainly focused on frequency-dependent selection (Benson, 1972; Mallet and Barton, 1989; Langham, 2004; Borer et al., 2010; Nokelainen et al., 2014) or mating preferences (Chouteau et al., 2016). Unlike vertebrates, however, insects have been well-studied at different life stages in relation to aposematic signals and their interplay with allelochemical sequestration (Marples et al., 1994; RoqueAlbelo et al., 2002), allowing the opportunity to study carry-over effects of early life on the adult expression of warning coloration and chemical defenses.

Multiples studies have focused on the striking warning signal polymorphism observed in some ladybeetles (family Coccinnelidae). For instance, Osawa and Nishida (1992) and Awad et al. (2015) showed that polymorphism in the elytra coloration of Harmonia axyridis is maintained either by seasonal mating variation or assortative mating (respectively; Osawa and Nishida, 1992; Awad et al., 2015). In Adalia bipunctata, in contrast, the polymorphism is maintained by assortative mating coupled with inheritance of female preference (Majerus et al., 1982), showing negative frequency-dependent mating selection (i.e., females prefer the rare morph; O'Donald and Majerus, 1984).

Another group in which these two selective pressures have been widely studied is the Neotropical butterflies of the genus Heliconius. These butterflies, which occur in Central and Northern South America, are characterized by wings with conspicuous markings (e.g., yellow, white, red, etc.) on a dark background, which inform predators about the possession of cyanide compounds that make them toxic (Nahrstedt and Davis, 1983; Zagrobelny et al., 2004; Cardoso and Gilbert, 2013). In this genus, the evolution of distinct color patterns between populations has been extensively explained in the context of Müllerian mimicry, in which a warningly colored aposematic species mimics the appearance of another one to share the costs of predator education (Müller, 1879). Although both the composition and spatial variation of the predator communities selecting for this resemblance in their coloration are still unknown (Merrill et al., 2015), these mimetic species have become a textbook example of natural selection (Jiggins, 2017). However, others studies have also explored how sexual selection, via mate choice and assortative mating (Jiggins et al., 2001; Estrada and Jiggins, 2008; Merrill Richard et al., 2014), has shaped wing coloration. For example, in a recent study, Finkbeiner et al. (2014) tested the relative importance of color and pattern in predation avoidance and mate choice in Heliconius erato. The authors found that although the right combination of local color and pattern provided the highest deterrence and mate attraction, color seemed to be more important than pattern, suggesting that sexual and natural selection work in parallel to influence the evolution of warning coloration in this species (Finkbeiner et al., 2014). 


\section{Interactive Effects of Natural and Sexual Selection May Lead to Population Divergence and Speciation}

Inter-population variation in multimodal warning signals provides an opportunity for unraveling how populations diverge and, eventually, in some cases, how new species originate. This can also occur through the joint effect of natural and sexual selection on aposematic traits (Maan and Seehausen, 2011). Population divergence through natural selection alone would require extreme combinations of parameters (e.g., almost null migration and strong selection for ecological specialization) to be fulfilled because gene flow would decrease the level of diversification (Mayr, 1963). Therefore, the effects of sexual selection are required to promote sexual isolation (through preand post-zygotic mechanisms), together with the effect of linkage disequilibrium to maintain the traits correlated and inherited by the following generation (Servedio, 2009). This interplay is particularly important for ecological speciation in sympatry, which occurs when reproductive isolation has evolved as an adaptation to different environments (reviewed in Rice and Hostert, 2017), or through hybridization, which can generate novel traits capitalizing on existing variation between related species (Mallet, 2007; Salazar et al., 2010). Additionally, the relaxation of predation pressure on aposematic species leaves room for traits to be selected by sexual selection, especially if predators associate these mating signals with unprofitability.

As seen in the previous section, poison frogs (family Dendrobatidae) can use warning coloration as a mating signal. However, the predominant modality of anuran mating signals is acoustic (i.e., advertisement calls). A recent study by Santos et al. (2014) demonstrated that acoustic mating signals in poison frogs (Dendrobatidae) have diversified in association with aposematism due to sexual selection, such that aposematic species have calls with a set of characteristics that differ from those of non-aposematic species (Santos et al., 2014). The level of conspicuousness in different populations of O. pumilio also predicts other aspects of the sexual display behavior, with males from more conspicuous populations calling from more exposed sites (Pröhl and Ostrowski, 2011; Rudh et al., 2011), and being more aggressive and explorative (Rudh et al., 2013). These behavioral differences coupled with mechanisms such as assortative mating could generate pre-zygotic isolation leading to population divergence, in the first place, and potentially to a speciation process in the long term. Indeed, in O. pumilio, molecular approaches show that color, but not body size, is diverging at high rates, indicating selection (Wang and Shaffer, 2008; Brown et al., 2010). Moreover, these studies demonstrate that sexual and natural selection are causing genetic isolation between different color morphs in the wild, which could be a sign of incipient speciation (Wang and Summers, 2010). This is supported by recent findings showing that, within Dendrobatidae, the aposematic lineages are speciating at higher rates than their non-aposematic counterparts (Santos et al., 2014).

The synergistic effects of sexual selection and natural selection are also likely to affect speciation processes in Heliconius butterflies. The color and pattern of their wings (reviewed in Jiggins, 2017), coupled to a very characteristic flight behavior (Srygley, 1999), help predators recognize and subsequently avoid them, but the former are also involved in mate recognition. This suggests that the ultimate fitness of individuals displaying different combinations of these traits is determined by both synergies and compromises between the different functions (Merrill et al., 2015). Several of these species belong to local mimicry rings, making their appearance the subject of strong purifying selection, but also strong assortative mating (Jiggins et al., 2001). Under these conditions, novel forms are punished by a higher predation due to frequency-dependent selection (Mallet and Barton, 1989). Hybrids would be expected to have the same fate if their appearance deviates from the parental phenotype(s) (Merrill et al., 2012); however, one of the most fascinating aspects of this system is that hybridization has offered a route to speciation (Mavárez et al., 2006; Mallet, 2007; Salazar et al., 2010). Wing color patterns in Heliconius are thus involved in predator deterrence, species recognition, and mating preferences. However, colors can be only one component of a multimodal mating signal that also involve chemical components, e.g., pheromones. Even in a community consisting of mimetic species, visual attraction can be based at first on wing appearance, yet at a shorter range scents from the wings and the genitalia can provide species-specific chemical signatures leading to assortative mating (Mérot et al., 2015).

\section{Chemical Compounds Can Play a Role in Mate Attraction and Predator Deterrence-But Could They Also Have a Dual Function?}

Insects offer a prime example of sexual communication mediated by chemical signals such as pheromones. As such, the divergence in pheromone components has shown to play a key role also in speciation (Groot et al., 2006, 2009). Pheromone composition and variability have been studied in detail in bella moths, Utheteisa ornatrix (Conner et al., 1981), moths in the genus Heliotis (Klun et al., 1980; Teal et al., 1984; Heath et al., 1991) and bark beetles (genus Ips; Lanier et al., 1980; Seybold et al., 1995). As well as long-range pheromones, cuticular hydrocarbons (or CHCs) have also been shown to play an important role in intraspecific communication and mate choice in insects (Sharma Manmohan et al., 2011; Ingleby, 2015).

The use of defensive chemicals is also widespread throughout insects. In addition to their crucial role in predator deterrence, a linkage between defensive chemicals and intraspecific communication has been shown in many insect species. For instance, in Lepidoptera, different families (e.g., Nymphalidae, Danaidae, and Erebidae) use secondary compounds such as pyrrolizidine alkaloids in male courtship displays, nuptial gifts, and egg protection (Boppré et al., 1978; Brown, 1984; Moore et al., 1990; Weller et al., 1999). For example, males of U. ornatrix, have glandular structures in which they store pyrrolizines. Males unable to produce certain compound derived from these alkaloids have been found to be less successful at courting females (Conner et al., 1981). In fact, it has been suggested that 
this compound is used by females to assess the extent to which the male is chemically protected (Conner et al., 1981). A similar example can be found in the beetle Neopyrochroa flabellate (Eisner et al., 1996a,b).

However, we currently have very little information on whether sexual selection and natural selection shape the secondary defenses synergistically. In some aposematic species, levels of secondary defense have shown to differ between females and males at the reproductive life-stage, which may suggest differential selection. For example, burying beetles (Nicrophorus vespilloides) use their anal exudates both for their own defense and the protection of their offspring, and females appear to produce more of these exudates than males (Lindstedt et al., 2017). Allocation for chemical defense has also shown to trade off with reproductive success indicating that these two functions could play important role in both mate attraction and predator deterrence (Nokelainen et al., 2012). This interaction is further complicated by the fact that many species sequester their chemical defenses from their diet. In the true bug Lygaeus equestris, for example, diet, and therefore level of chemical defense, has no effect on mate choice (Burdfield-Steel et al., 2013). This is despite evidence that females of this species pass defensive chemicals on to their eggs, protecting them from predators (Newcombe et al., 2013). When variation between individuals is purely environmental, effects on mate choice may only occur when direct benefits are high (as in several of the examples given above), although see (Geiselhardt et al., 2012) for an example of diet and host plant leading to associative mating based on CHC (cuticular hydrocarbons) profile. When direct benefits are low, species in which chemical defense level is either genetically determined, or indicative of overall quality, may be better candidates in which to look for mate choice based on defense level. This may well be the case in species that produce their defenses de novo.

\section{MOVING TOWARD A MORE INTEGRATED VIEW OF APOSEMATIC SIGNALS}

Despite all the examples discussed so far, it is clear that only a few studies address how both natural and sexual selection act (either synergistically or antagonistically) on the evolution of multimodal aposematic signals. Furthermore, it is apparent that not only color, but also odor, taste, and behavior are part of warning displays, and their interaction, besides strengthening the signal, can provide reliable information about the quality of the emitter. Yet, only a handful of studies have considered the interplay among these, and their joint significance remains barely tested. To corroborate these impressions, we conducted a literature search in Web of Science and analyzed the contents of a representative sample of the articles available on aposematism. We used the search terms "aposematism or aposematic" to have the widest spectrum possible of studies and organisms, and limited the search to articles published in or after 1990 and until mid-April 2018. This search rendered a total of 1,051 articles, out of which we analyzed 105 (10\%) selected as explained below.
Because taking the first (or last) articles in the search list would have constrained the timeframe, we took the first $10 \%$ of the number of articles published each year, which varied between 10 in 1990 and 87 in 2017 (Figure 5), that fitted the following criteria. We only included articles studying an actual natural animal system (i.e., no plants), and assessing directly or indirectly the effect of natural (predation) and/or sexual selection in the signals considered. Therefore, studies done with artificial prey represented as symbols or using artificial chemicals were excluded. Artificial prey were accepted if they aimed to represent the actual animal studied, as in dummies or models. We also excluded taxonomic descriptions, as well as phylogenetic and phylogeographic studies in which there was no direct relation with the selection pressures on which we focus this review. For each paper we recorded the focal species identity, the trait(s) studied, whether or not they consider the multimodality aspect, and the type of selection addressed (Table 1).

As revealed by our search, aposematism is a phenomenon that has raised increasing interest among researchers over the last three decades (Figure 5), and has been studied in a variety of organisms (Figure 3), spanning gastropods through to carnivores. Nevertheless, invertebrates seem to be studied more, in $\sim 69 \%$ of the cases (Figure 6A); perhaps not surprising considering they cover $97 \%$ of organisms on earth. Both within invertebrates and vertebrates, there are taxonomic groups accounting for the majority of the studies (Figure 6A). Among invertebrates, the best studied are lepidopterans (34.2\%), such as longwings (5.7\%), coleopterans (20.5\%), and other insects (34.2\%). Among vertebrates, poison frogs are undoubtedly the group that has stimulated most research (68.9\%), followed by snakes (18.2\%; Figure 6A).

Regardless of the taxonomic group, most studies have focused on unimodal signals, particularly visual (59.4\%), and chemical (16\%; Figure 6B). Multimodal signals were studied only in $17.9 \%$ of the cases, and consisted in all cases of visual signals in

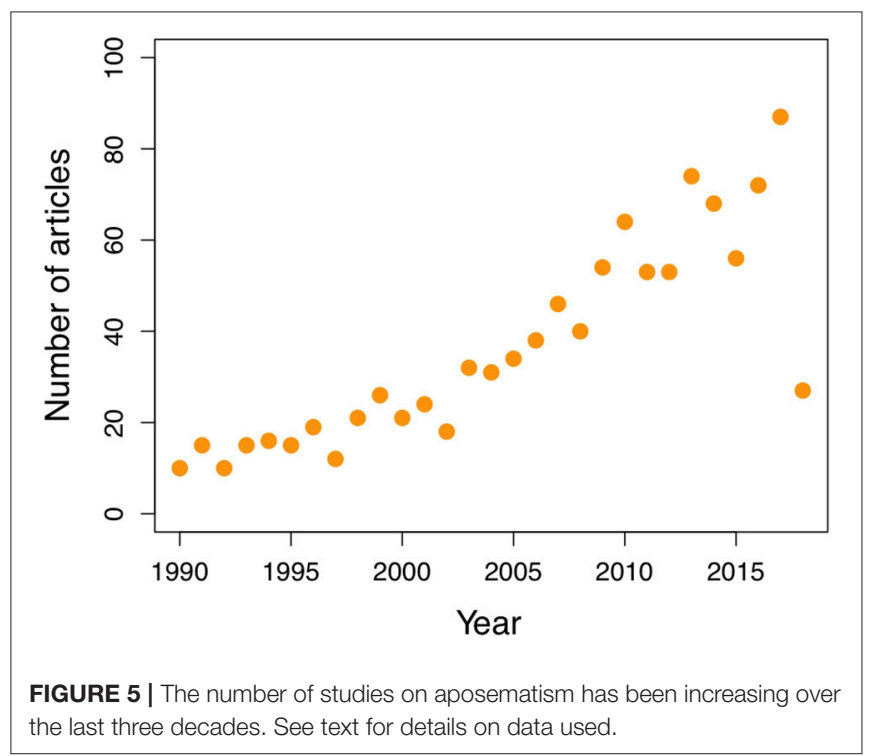


TABLE 1 | Studies included in the review of literature published on aposematism over the last three decades.

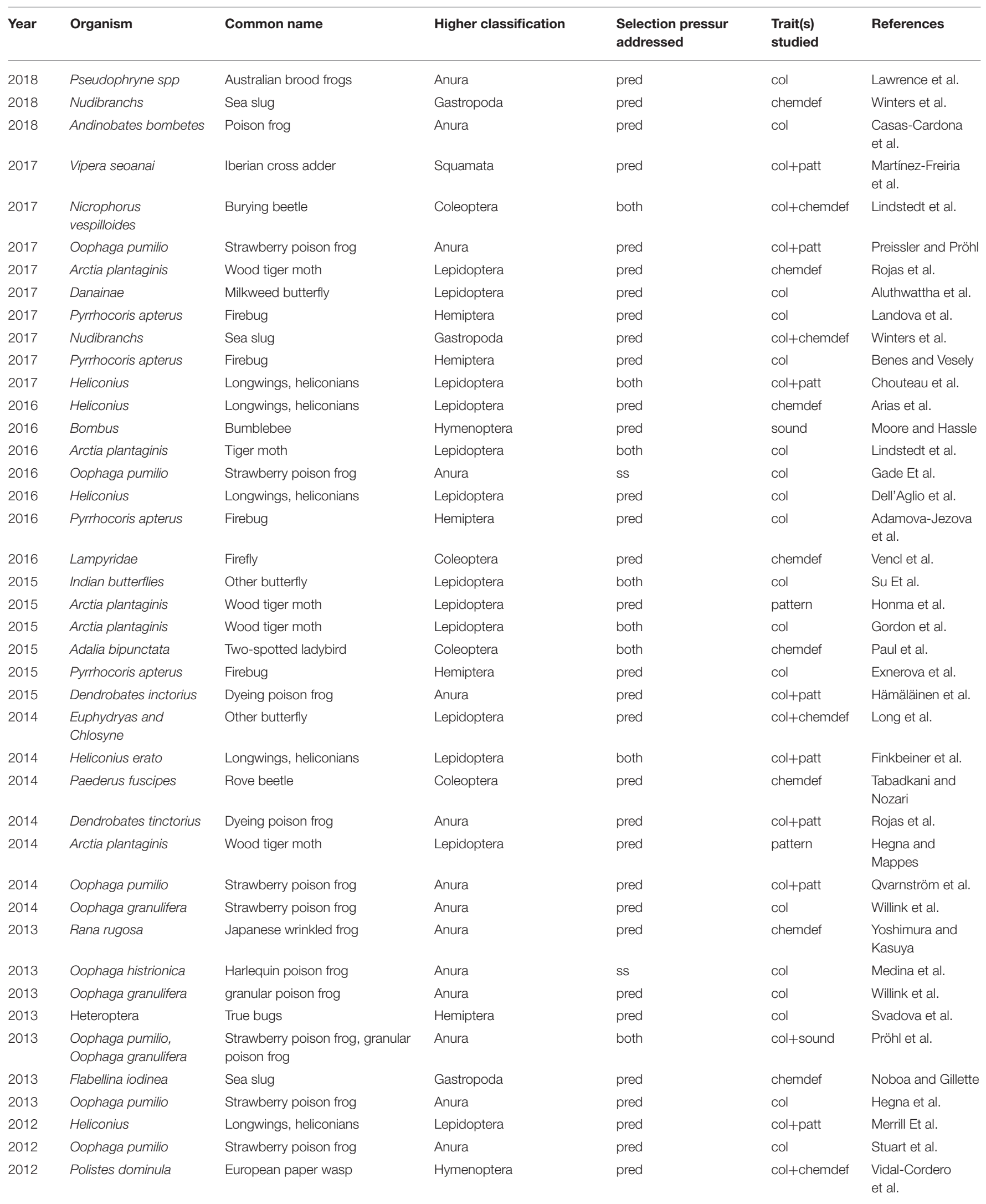


TABLE 1 | Continued

\begin{tabular}{|c|c|c|c|c|c|c|}
\hline Year & Organism & Common name & Higher classification & $\begin{array}{l}\text { Selection pressur } \\
\text { addressed }\end{array}$ & $\begin{array}{l}\text { Trait(s) } \\
\text { studied }\end{array}$ & References \\
\hline 2012 & Vipera spp. & European vipers & Squamata & pred & col+patt & Valkonen et al. \\
\hline 2012 & True bugs & True bugs & Hemiptera & pred & chemdef & Noge et al. \\
\hline 2011 & Ranitomeya imitator & Mimic poison frog & Anura & pred & $\mathrm{col}$ & $\begin{array}{l}\text { Chouteau and } \\
\text { Angers }\end{array}$ \\
\hline 2011 & Lycorma delicatula & Spotted lanternfly & Hemiptera & pred & $\mathrm{col}$ & Kang et al. \\
\hline 2011 & Motyxia spp & Millipede & Myriapoda & pred & luminescence & Marek et al. \\
\hline 2011 & Oophaga pumilio & Strawberry poison frog & Anura & both & $\mathrm{col}$ & Ozel and Stynoski \\
\hline 2011 & Cynops pyrrhogaster & Japanese fire belly newt & Caudata & pred & $\mathrm{col}$ & Mochida \\
\hline 2010 & Oreina gloriosa & Leaf beetles & Coleoptera & pred & $\mathrm{col}$ & Borer et al. \\
\hline 2010 & Graphosoma lineatum & Shield bugs & Hemiptera & pred & $\mathrm{col}$ & Johansen et al. \\
\hline 2010 & Bombus spp & Bumblebee & Hymenoptera & pred & $\mathrm{col}$ & Stelzer et al. \\
\hline 2010 & Pyrrhocoris apterus & Firebug & Hemiptera & pred & col+size & Prokopova et al. \\
\hline 2010 & Opistobranchs & Sea slug & Gastropoda & pred & col+chemdef & $\begin{array}{l}\text { Cortesi and } \\
\text { Cheney }\end{array}$ \\
\hline 2010 & $\begin{array}{l}\text { Hypselodoris } \\
\text { fontandraui }\end{array}$ & Sea slug & Gastropoda & pred & col+chemdef & Haber et al. \\
\hline 2009 & Oophaga pumilio & Strawberry poison frog & Anura & ss & $\mathrm{col}$ & $\begin{array}{l}\text { Maan and } \\
\text { Cummings }\end{array}$ \\
\hline 2009 & Mephitis mephitis & Skunk & Carnivora & pred & col+shape & Hunter \\
\hline 2009 & Photinus & Firefly & Coleoptera & pred & luminescence & Moosman et al. \\
\hline 2009 & Ladybirds & Ladybird & Coleoptera & pred & pattern+shape & Dolenska et al. \\
\hline 2009 & Tiger moths & Tiger moth & Lepidoptera & pred & sound & Barber et al. \\
\hline 2008 & Tiger moths & Tiger moth & Lepidoptera & pred & col+sound & $\begin{array}{l}\text { Ratcliffe and } \\
\text { Nydam }\end{array}$ \\
\hline 2008 & Oophaga pumilio & Strawberry poison frog & Anura & ss & $\mathrm{col}$ & $\begin{array}{l}\text { Maan and } \\
\text { Cummings }\end{array}$ \\
\hline 2008 & Carabid beetles & Ground beetle & Coleoptera & pred & col+chemdef & Bonacci et al. \\
\hline 2008 & Lycidae beetles & Net-winged beetle & Coleoptera & pred & chemdef & Eisner et al. \\
\hline 2007 & Oophaga pumilio & Strawberry poison frog & Anura & pred & $\mathrm{col}$ & Saporito et al. \\
\hline 2007 & Cirriformia punctata & Polychaete & Polychaeta & pred & chemdef & Meredith et al. \\
\hline 2007 & Oophaga pumilio & Strawberry poison frog & Anura & ss & $\mathrm{col}$ & $\begin{array}{l}\text { Reynolds and } \\
\text { Fitzpatrick }\end{array}$ \\
\hline 2007 & Harmonia axyridis & Asian ladybeetle & Coleoptera & pred & col+chemdef & Bezzerides et al. \\
\hline 2007 & Tiger moths & Tiger moth & Lepidoptera & pred & sound & $\begin{array}{l}\text { Barber and } \\
\text { Conner }\end{array}$ \\
\hline 2006 & Micrurus phyrrocryptus & Coral snake & Squamata & pred & colpatt & Buasso et al. \\
\hline 2006 & Carabid beetles & Ground beetle & Coleoptera & pred & col+chemdef & Bonacci et al. \\
\hline 2006 & Graphosoma lineatum & Shield bugs & Hemiptera & pred & col+chemdef & Veseley et al. \\
\hline 2006 & Pyrrhocoris apterus & Firebug & Hemiptera & pred & $\mathrm{col}$ & Exnerova et al. \\
\hline 2005 & Cycnia tenera & Tiger moth & Lepidoptera & pred & sound & $\begin{array}{l}\text { Ratcliffe and } \\
\text { Fullard }\end{array}$ \\
\hline 2005 & Vipera berus & Common European adder & Squamata & pred & pattern & $\begin{array}{l}\text { Niskanen and } \\
\text { Mappes }\end{array}$ \\
\hline 2005 & $\begin{array}{l}\text { Ensatina eschscholtzii } \\
\text { xanthoptica }\end{array}$ & Lungless salamander & Caudata & pred & $\mathrm{col}$ & Kuchta \\
\hline 2004 & Vipera berus & Common European adder & Squamata & pred & pattern & Wüster et al. \\
\hline 2004 & Heliconius & Longwings, heliconians & Lepidoptera & pred & col+patt & Langham \\
\hline 2004 & Oophaga pumilio & Strawberry poison frog & Anura & both & $\mathrm{col}$ & Siddiqi et al. \\
\hline 2003 & Poison frogs & Poison frog & Anura & pred & col+size & $\begin{array}{l}\text { Hagman and } \\
\text { Forsman }\end{array}$ \\
\hline 2003 & Poison frogs & Poison frog & Anura & pred & col+chemdef & Santos et al. \\
\hline
\end{tabular}


TABLE 1 | Continued

\begin{tabular}{|c|c|c|c|c|c|c|}
\hline Year & Organism & Common name & Higher classification & $\begin{array}{l}\text { Selection pressur } \\
\text { addressed }\end{array}$ & $\begin{array}{l}\text { Trait(s) } \\
\text { studied }\end{array}$ & References \\
\hline 2003 & Vespula norwegica & Norwegian wasp & Hymenoptera & pred & col+shape & $\begin{array}{l}\text { Kauppinen and } \\
\text { Mappes }\end{array}$ \\
\hline 2002 & Eumaeus minyas & Lycaenid butterfly & Lepidoptera & pred & chemdef & $\begin{array}{l}\text { Castillo-Guevara } \\
\text { and Rico-Gray }\end{array}$ \\
\hline 2002 & Murgantia histrionica & Harlequin bug & Hemiptera & pred & chemdef & Aliabadi et al. \\
\hline 2001 & Pseudoxycheila tasalis & Neotropical tiger beetle & Coleoptera & pred & $\mathrm{col}$ & Schultz \\
\hline 2001 & Pseudoxycheila tasalis & Neotropical tiger beetle & Coleoptera & pred & chemdef & $\begin{array}{l}\text { Schultz and } \\
\text { Puchalski }\end{array}$ \\
\hline 2000 & Cercopidae & Froghopper & Hemiptera & pred & col+chemdef & Peck \\
\hline 2000 & Schistocerca gregaria & Desert locust & Orthoptera & pred & col+chemdef & Sword et al. \\
\hline 1999 & $\begin{array}{l}\text { Cosmopepla } \\
\text { bimaculata }\end{array}$ & Stink bug & Hemiptera & pred & chemdef & Krall et al. \\
\hline 1999 & Nudibranchs & Sea slug & Gastropoda & pred & $\mathrm{col}$ & $\begin{array}{l}\text { Giménez- } \\
\text { Casalduero } \\
\text { et al. }\end{array}$ \\
\hline 1999 & Bombus terrestris & Buff-tailed bumblebee & Hymenoptera & pred & sound & $\begin{array}{l}\text { Kirschner and } \\
\text { Roschard }\end{array}$ \\
\hline 1998 & Romalea guttata & Lubber grasshopper & Orthoptera & pred & col+behav & $\begin{array}{l}\text { Hatle and } \\
\text { Faragher }\end{array}$ \\
\hline 1998 & Flatworms & Flatworms & Platyhelminthes & pred & $\mathrm{col}$ & Ang and Newman \\
\hline 1997 & $\begin{array}{l}\text { Ithomiine and tiger } \\
\text { moths }\end{array}$ & Tiger moth & Lepidoptera & pred & chemdef & Cardoso \\
\hline 1996 & Neotropical butterflies & Neotropical butterflies & Lepidoptera & pred & col+behav & Pinheiro \\
\hline 1996 & Mephitis mephitis & Striped skunk & Carnivora & pred & sound+behav & $\begin{array}{l}\text { Lartviere and } \\
\text { Messier }\end{array}$ \\
\hline 1995 & Tiger moths & Tiger moth & Lepidoptera & pred & sound & $\begin{array}{l}\text { Dunning and } \\
\text { Kruger }\end{array}$ \\
\hline 1995 & Coral snakes & Coral snake & Squamata & pred & col+patt & Brodie and Janzen \\
\hline 1994 & $\begin{array}{l}\text { Coccinella } \\
\text { septempunctata }\end{array}$ & Seven-spot ladybird & Coleoptera & pred & col+chemdef & Marples et al. \\
\hline 1994 & Opistobranchs & Sea slug & Gastropoda & pred & col+chemdef & Tullrot \\
\hline 1993 & Catocala spp & Underwing moths & Lepidoptera & pred & $\mathrm{col}$ & Ingalls \\
\hline 1993 & Monistria concinna & Grasshopper & Orthoptera & pred & col+chemdef & $\begin{array}{l}\text { Groeters and } \\
\text { Strong }\end{array}$ \\
\hline 1992 & Tiger moths & Tiger moth & Lepidoptera & pred & sound & Dunning et al. \\
\hline 1991 & Polycera quadrilineata & Sea slug & Gastropoda & pred & $\mathrm{col}$ & $\begin{array}{l}\text { Tullrot and } \\
\text { Sundberg }\end{array}$ \\
\hline 1991 & Leaf beetles & Leaf beetle & Coleoptera & pred & chemdef & $\begin{array}{l}\text { Pasteels and } \\
\text { Rowellrahier }\end{array}$ \\
\hline 1990 & Battus philenor & Blue swallowtail & Lepidoptera & pred & $\mathrm{col}$ & $\begin{array}{l}\text { Codella and } \\
\text { Lederhouse }\end{array}$ \\
\hline
\end{tabular}

See main text for details on inclusion criteria. pred, predation; ss, sexual selection; col, color; patt, pattern; chemdef, chemical defenses.

References in chronological order (from oldest to newest): (Codella and Lederhouse, 1990; Pasteels and Rowellrahier, 1991; Tullrot and Sundberg, 1991; Dunning et al., 1992; Groeters and Strong, 1993; Ingalls, 1993; Marples et al., 1994; Tullrot, 1994; Brodie and Janzen, 1995; Dunning and Kruger, 1995, 1996; Lartviere and Messier, 1996; Pinheiro, 1996; Cardoso, 1997; Ang and Newman, 1998; Hatle and Faragher, 1998; Gimenez-Casalduero et al., 1999; Kirchner and Roschard, 1999; Krall et al., 1999; Peck, 2000; Sword et al., 2000; Schultz, 2001; Schultz and Puchalski, 2001; Aliabadi et al., 2002; Castillo-Guevara and Rico-Gray, 2002; Kauppinen and Mappes, 2003; Santos et al., 2003; Langham, 2004; Siddiqi et al., 2004; Wuster et al., 2004; Kuchta, 2005; Niskanen and Mappes, 2005; Bonacci et al., 2006, 2008; Buasso et al., 2006; Exnerová et al., 2006, 2015; Vesely et al., 2006; Barber and Conner, 2007; Bezzerides et al., 2007; Meredith et al., 2007; Reynolds and Fitzpatrick, 2007; Saporito et al., 2007; Eisner et al., 2008; Maan and Cummings, 2008, 2009; Ratcliffe and Nydam, 2008; Barber et al., 2009; Dolenska et al., 2009; Hunter, 2009; Moosman et al., 2009; Borer et al., 2010; Cortesi and Cheney, 2010; Haber et al., 2010; Johansen et al., 2010; Prokopova et al., 2010; Stelzer et al., 2010; Chouteau and Angers, 2011; Kang et al., 2011; Marek et al., 2011; Mochida, 2011; Ozel and Stynoski, 2011; Pröhl and Ostrowski, 2011; Merrill et al., 2012; Noge et al., 2012; Stuart et al., 2012; Valkonen et al., 2012; Vidal-Cordero et al., 2012; Hegna et al., 2013; Medina et al., 2013; Noboa and Gillette, 2013; Pröhl et al., 2013; Svadová et al., 2013; Willink et al., 2013, 2014; Yoshimura and Kasuya, 2013; Finkbeiner et al., 2014; Hegna and Mappes, 2014; Long et al., 2014; Qvarnström et al., 2014; Rojas et al., 2014, 2017; Tabadkani and Nozari, 2014; Gordon et al., 2015; Hämäläinen et al., 2015; Honma et al., 2015; Su et al., 2015; Adamova-Jezova et al., 2016; Arias et al., 2016; Dell'aglio et al., 2016; Gade et al., 2016; Lindstedt et al., 2016, 2017; Moore and Hassall, 2016; Vencl et al., 2016; Aluthwattha et al., 2017; Benes and Vesely, 2017; Chouteau et al., 2017; Landová et al., 2017; Martinez-Freiria et al., 2017; Preissler and Pröhl, 2017; Winters et al., 2017, 2018; Casas-Cardona et al., 2018; Lawrence et al., 2018). 

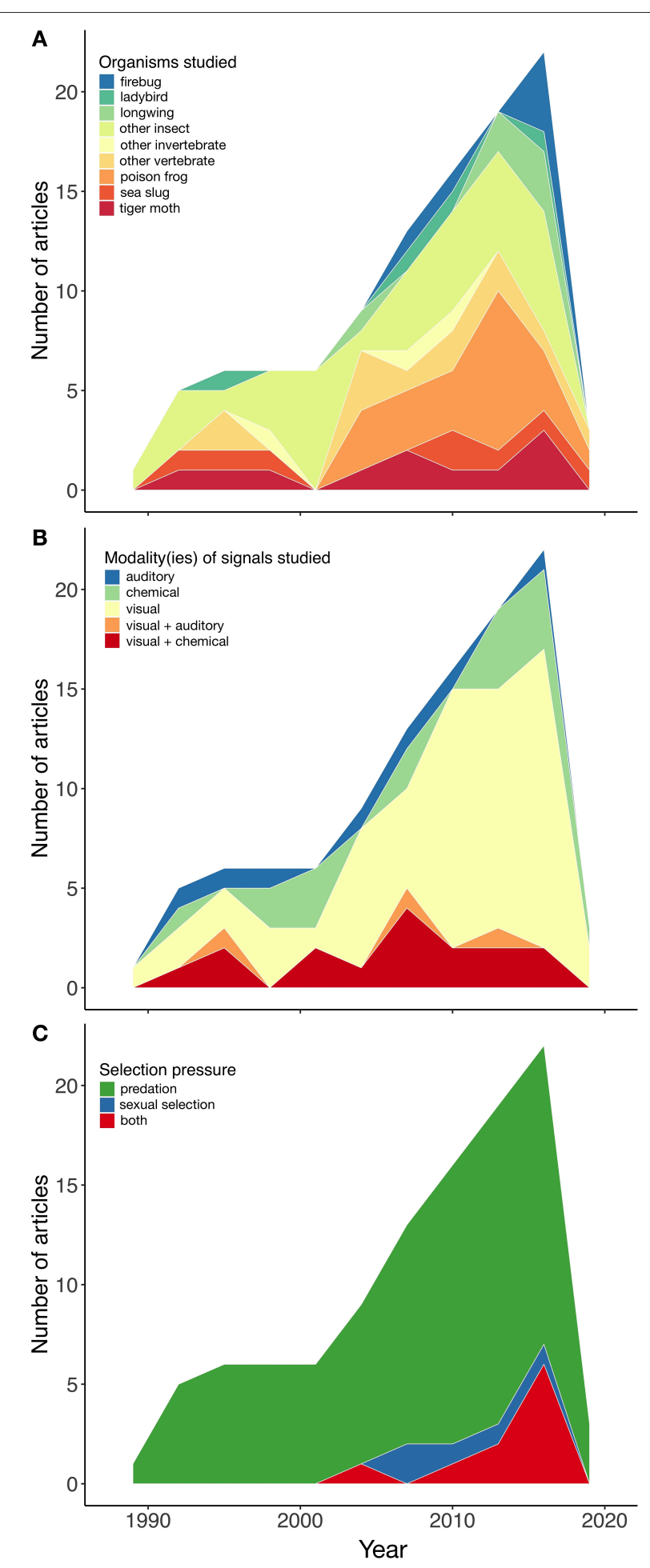

FIGURE 6 | (A) Representative animal groups studied in relation to aposematism over the last three decades. The larger the area, the more studies on that particular group. (B) Signaling modalities studied in relation to aposematism over the last three decades. The larger the area, the more studied. (C) Selection pressures taken into account in studies on aposematism over the last three decades. The larger the area, the more studies taking that particular selective pressure into account. combination with either chemical defenses $(15.1 \%)$ or auditory signals (2.8\%; Figure 6B).

Not surprisingly, most studies on aposematism have addressed either directly or indirectly the effect of natural selection (predation) on the studied signals. As pointed out above, however, there is an increasing interest in systems or contexts in which the effect of both natural and sexual selection can be studied simultaneously. Of all the studies reviewed, only $4.7 \%$ addressed exclusively the effect of sexual selection on warning signals, while $9.4 \%$ investigated the effects of both selective forces jointly (Figure 6C). Most importantly, studies in which the effects of natural and sexual selection are investigated at the same time tend to focus only on one sensory modality, in particular the visual, even if two components of a signal, for example color and pattern, are taken into account. This tendency seems to be as true for vertebrates, as it is for invertebrates (Figure 7).

Studies addressing the influence of predation on multimodal signals seem to be slightly more common in invertebrates than in vertebrates (Figure 7). This is most likely because insects, the invertebrate group most studied in this context, can be more easily bred and kept in the laboratory due to their shortgeneration times and numerous offspring, and studied under manipulated conditions. Moreover, in many cases it is easier to disentangle the visual and chemical components of their multimodal warning displays (Marples et al., 1994; Rönkä et al., 2018a,b). Most importantly, the overrepresentation of some groups in these studies may be partially due to the dynamics of predator-prey coevolution and the speed to respond to selection (Härlin and Härlin, 2003). These may favor aposematism in organisms such as insects, amphibians, or reptiles, which lean toward an $r$-strategy (numerous offspring, high growth rate and low per capita probability of survival), while constraining it in organisms such as mammals and birds, which lean toward a K-strategy (few offspring, low growth rate and high per capita probability of survival), and are more often the selective agents.

To investigate this further, not only do we need new model species with well-studied visual signals and chemical communication, but also where the traits in question are heritable, and known to be under identified selective pressures (i.e., predation and sexual selection). Here, we propose the wood tiger moth, A. plantaginis, as one of such emerging model species where multimodal warning displays can be studied while addressing conflictive or synergistic selective pressures, as stated below.

\section{THE WOOD TIGER MOTH AS A PROMISING MODEL TO STUDY MULTIMODALITY IN APOSEMATIC AND SEXUAL SIGNALING}

One of the species in which multimodal aposematic signals have been studied in depth is A. plantaginis (formerly Parasemia plantaginis; Rönkä et al., 2016), the wood tiger moth (Figure 8). A. plantaginis is an aposematic diurnal moth with a widespread 

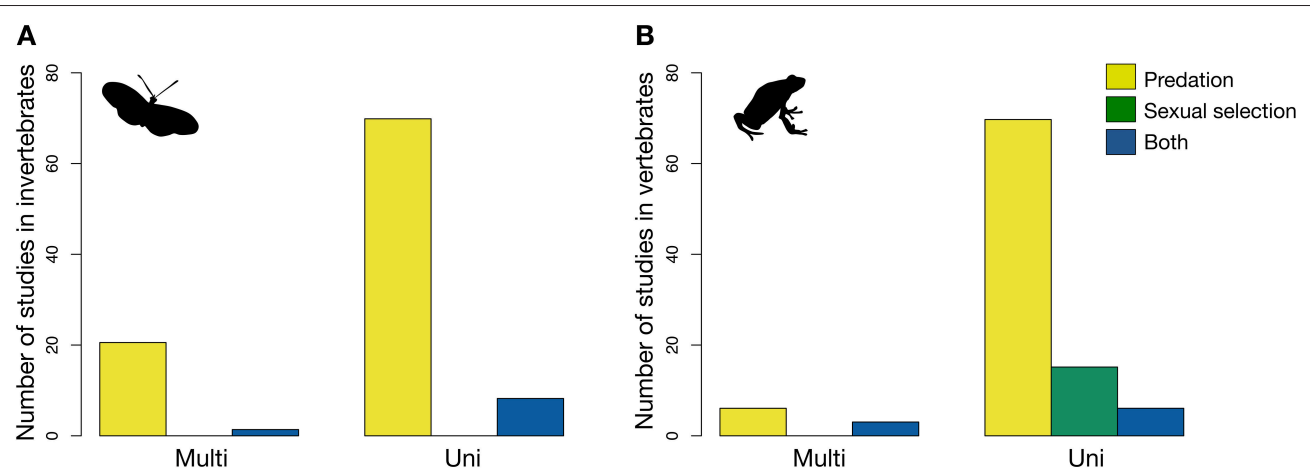

FIGURE 7 | Number of studies that address the effects of predation, sexual selection, or both on one (unimodal) or two (multimodal) signals in the aposematic displays of $(\mathbf{A})$ invertebrates, and $\mathbf{( B )}$ vertebrates.
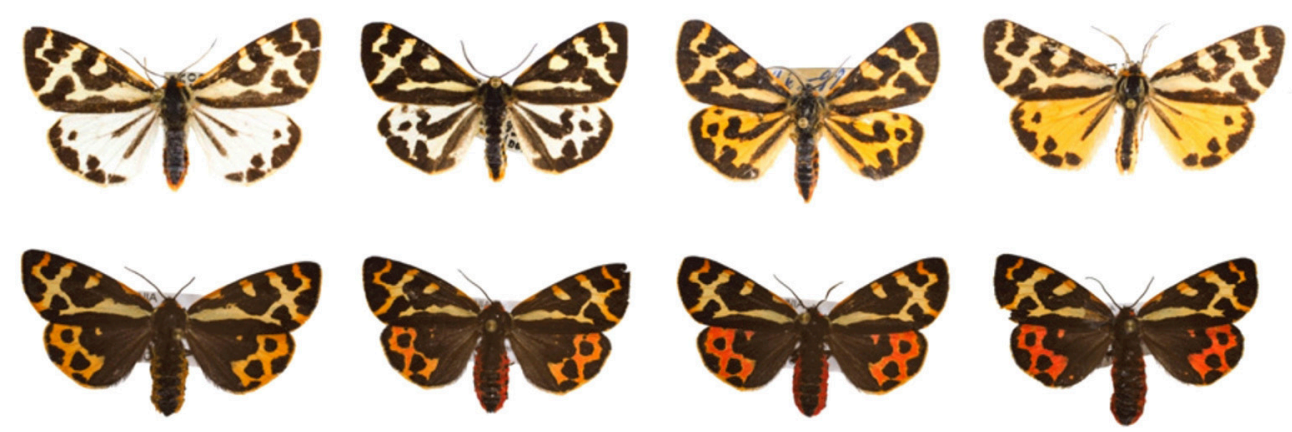

FIGURE 8 | The different morphs of the wood tiger moth in Europe. The upper row shows polymorphic color variation in males, whereas the bottom row showcases the continuous variation observed in females. Reproduced with permission from Nokelainen (2013). Photos: S. Waldron.

geographic distribution across the holarctic region (Hegna et al., 2015). Larvae of this species are polyphagous, feeding on a large number of different genera (Ojala et al., 2005), and overwinter at their 4 th -5 th instar. The adult stage lasts for about 2-3 weeks during which these moths do not feed. This means that both their coloration and chemical defenses are set at the larval stage (Ojala et al., 2005). Males spend their adult life flying in search of females, who are ready to mate soon after eclosion.

While their coloration has been shown to have a strong hereditary component (Nokelainen et al., 2013; Lindstedt et al., 2016), diet can also influence adult coloration, particularly in females (Lindstedt et al., 2010; Furlanetto, 2017; Figure 9). In addition, their chemical defenses are affected by resource availability during early life (Brain, 2016; Furlanetto, 2017; Figure 9). As the moths are most active during daylight hours (Rojas et al., 2015a) they are vulnerable to predation by birds, particularly while resting on the vegetation, where they are clearly conspicuous (Nokelainen et al., 2012; Henze et al., 2018). Likewise, they can be vulnerable to attacks by invertebrate predators, especially when the temperature is not high enough for the moth to initiate flight, or when it is eclosing from the pupa and its wings are not yet fully extended. Adult moths defend themselves with two distinct defensive fluids, one produced from the anal tract and one from glands behind the head (Figure 9). The first is targeted toward invertebrate predators, while the second is targeted toward avian predators (Rojas et al., 2017) and contains pyrazines, which the moths produce de novo (BurdfieldSteel et al., 2018), likely on the basis of constituents obtained from their diet. These defenses are advertised to birds with brightly colored hindwings, where red, yellow, or even white coloration is contrasted with black patterning (Figure 8).

\section{Predation Is a Strong Selective Pressure on Wood Tiger Moth Warning Coloration and Chemical Defenses}

Surprisingly, given their role in predator deterrence, the hindwings of wood tiger moths show considerable color variation, both within and between populations (Hegna et al., 2015; Figure 8). In the Finnish population, which has been the focus of much of the research on this species, males show discrete color polymorphism, possessing either white or yellow hindwings, while females vary continuously from yellow to red. In contrast, in the putative ancestral populations (Caucasus) males exhibit continuous variation from yellow-orange through to red in their hindwing coloration, while females display red hindwings. The forewings, on the other hand, do not vary much within populations, and consist of high-contrast black and white patterning. Many studies to date have demonstrated the predatordeterrent nature of this moth's coloration (Lindstedt et al., 2011; 


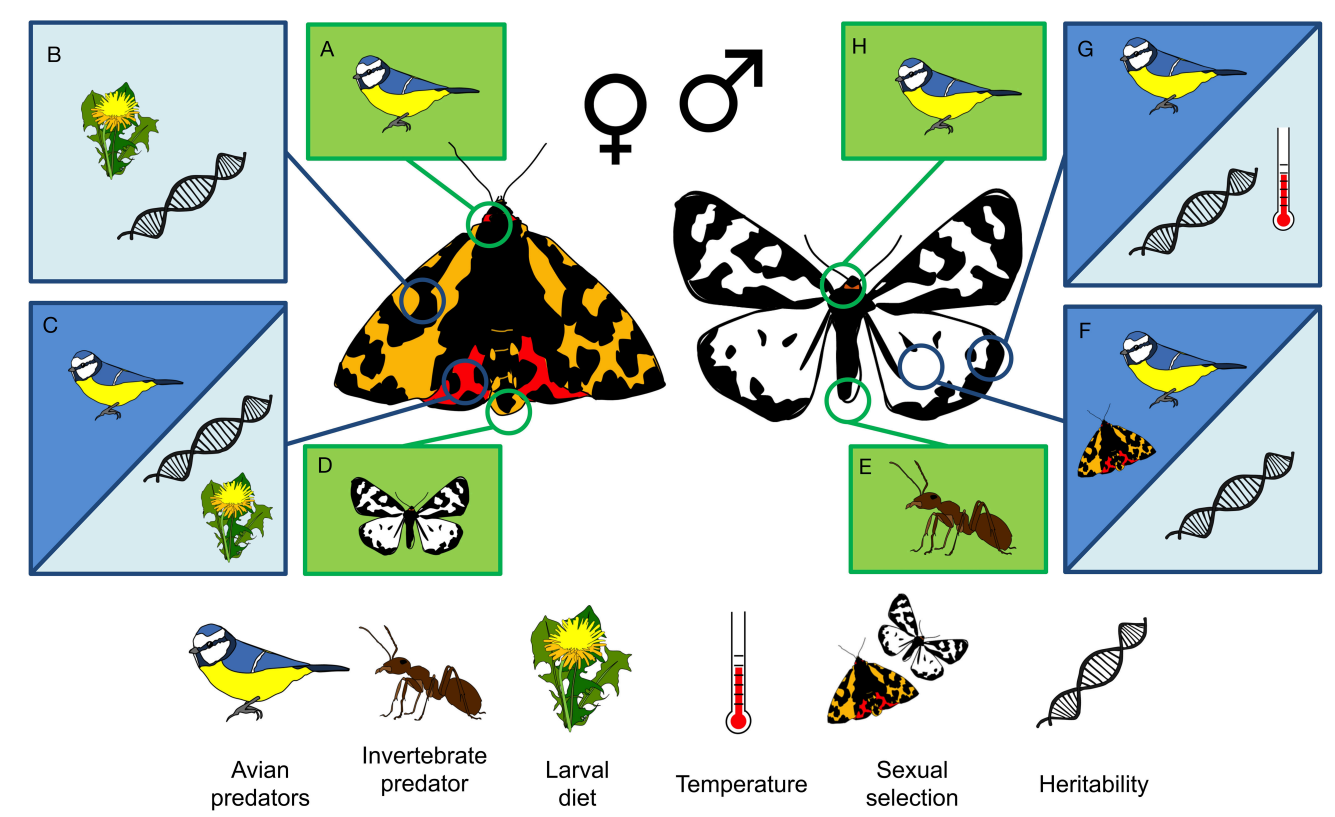

FIGURE 9 | A schematic illustration of the different selective (dark) and environmental (light) factors currently known to be acting on chemical (green) and visual (blue) signals in the wood tiger moth. Anti-clockwise from top left: (A) Female neck defensive fluids are deterrent to avian predators; (B) Female melanisation is heritable and influenced by larval diet; (C) Female hindwing coloration is highly heritable, affected by larval diet, and influences avian predation risk; (D) Males follow female pheromone trails; (E) Male abdominal defensive fluids deter invertebrate predators; (F) Male hindwing colouration is heritable and plays a role in both predator deterrence and male mating success; $(\mathbf{G})$ Male melanisation is heritable and influences both thermoregulation and predation risk; $(\mathbf{H})$ Male neck defensive fluids are deterrent to avian predators. See text for details.
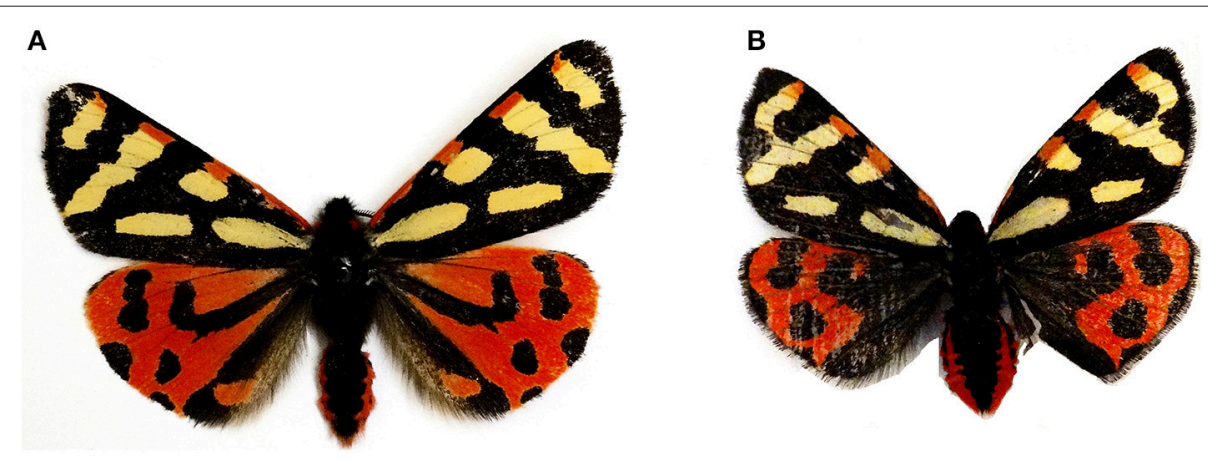

FIGURE 10 | Caucasian populations of the wood tiger moth are characterized by the lack of sexual dimorphism in hindwing colouration seen in Europe. In Georgia, both males (A) and females (B) exhibit hindwing coloration rich in long wavelengths resulting in continuous red-orange coloration. Photos: B. Rojas.

Nokelainen et al., 2012, 2014; Hegna and Mappes, 2014) and, lately, the same has been shown for its chemical defenses, even when experimentally decoupled from the visual signals (Brain, 2016; Rojas et al., 2017).

Male multimodal warning display has been shown to have important consequences for predator defense. A series of experiments using artificial moths showed that white males suffer higher predation rates in the field when compared to yellows (Nokelainen et al., 2014). Furthermore, when live moths were presented to birds, yellow males elicited longer attack latencies, suggesting yellow males possess stronger warning signals (Nokelainen et al., 2012). Yellow males seem to have more efficient chemical defenses against ants, and a more repulsive odor against avian predators when presented in isolation from the visual signal (Rojas et al., 2017), although the fluids of both morphs seem to be unpalatable even when presented in the absence of color cues. When the warning colors are presented to birds in association with the natural chemical defenses (the moth as a whole), however, white moths elicit more beak cleaning in great tits than yellow moths, and are also eaten less when attacked for the first time (Rönkä et al., 2018b). Thus, while yellow males seem to rely mostly on their warning color and repulsive odor to avoid being attacked, white males seem to rely on taste-rejection by predators, indicating that the multiple components of these 
moths' warning displays repel wild-caught predators at different stages of predation. Furthermore, white and yellow male color morphs trade-off between efficient warning and sexual signaling (see below). The white-colored males generally have a higher mating success (Nokelainen et al., 2012; Gordon et al., 2015) whereas the yellow-colored males are more avoided by avian predators (Nokelainen et al., 2012). Moreover, changes in the composition of the avian predator community can influence the direction of signal selection (Nokelainen et al., 2014), which, combined with spatial variation in differential mating success, may operate as a selection mosaic whereby dispersal facilitates the maintenance of genetic (Galarza et al., 2014), and hence phenotypic variation (Gordon et al., 2015).

Females are also well protected from predation. They, too, produce chemical defenses that deter birds effectively, but are costly to produce (Brain, 2016; Furlanetto, 2017). Red females are slightly more conspicuous (Lindstedt et al., 2011; Henze et al., 2018), and less frequently attacked by avian predators (Lindstedt et al., 2011) than orange ones, and experiments with wild-caught birds have demonstrated that the red coloration is learned faster than white and yellow (Rönkä et al., 2018a).

\section{Why Are the European Forms Sexually Dimorphic? The Emerging Role of Sexual Selection}

Sexual dimorphism, as well as sex-limited mimicry, are highly derived characters in many Lepidopteran systems (Kunte, 2008; Allen et al., 2010), but do occur multiple times in the Arctiinae. However, in Arctiina, the clade to which A. plantaginis belongs (Rönkä et al., 2016), sexual dimorphism is rare, suggesting that the ancestral state of the wood tiger moth is sexually monomorphic. Although the putative ancestral (Caucasian) forms of the species, as well as closely related species, exhibit a rather reddish coloration in both sexes (i.e., this population is not strictly sexually dichromatic; Rönkä et al., 2016; Figure 10), in a great portion of its range wood tiger moth morphs exhibit sexually dimorphic coloration (Hegna et al., 2015). Moreover, in several European populations white and yellow hind-winged males coexist locally, while females exhibit coloration that varies continuously from yellow through to orange and red.

Differences in reproductive allocation between males and females, and the subsequent differences in mate-searching behavior, can lead to differential exposure of the two sexes to predation. Female wood tiger moths, like many Lepidopteran females, allocate more resources to reproduction than to flight, eclosing with eggs ready to be fertilized. As is typical for moths, females use pheromones to attract males, who fly long distances in search of mates. Not surprisingly, males show their activity peak at the same time as the peak in female pheromone calling (Rojas et al., 2015a). Once they detect a female in the distance, they follow the pheromone source with a characteristic zig-zag flight. During the last stage of approach, it is also possible that males can detect the females visually, as these are particularly conspicuous against the vegetation on which they rest and call (Henze et al., 2018). Indeed, male eyes are more sensitive (Henze et al., 2018), which makes sense considering that they do most of the flying and maneuvering while searching for females. These ecological and behavioral differences between the sexes make it likely that the optimal values of signaling and defenses against predators are not the same for females and males.

Although natural selection can work on sexually dimorphic signals, and can both restrict or enhance the evolution of differences between sexes, sexual selection has been put forward as the main driving force of sexual dimorphism in Lepidoptera (Shine, 1989; Allen et al., 2010). A recent study examining the visual capabilities of both male and female wood tiger moths indicated that these moths are unable to distinguish among the different shades of orange-red that a female could have in its hindwings (Henze et al., 2018); this suggests that female coloration, as well as the coloration of Caucasian males, is unlikely to be influenced by sexual selection. Females, in contrast, are capable of distinguishing between the yellow and white coloration of Finnish male hindwings (Henze et al., 2018), pointing at a possible role of sexual selection, perhaps via female choice, on male hindwing polymorphism. Interestingly, some studies have revealed differences between the two male morphs in mating success, with white males getting a mating advantage, particularly when more abundant (Gordon et al., 2015) or when males are stressed/have costs imposed upon them (Nokelainen et al., 2012). Altogether, this hints at a role of coloration in mate choice or attraction, providing a possible explanation to wood tiger moths' sexual dimorphism in coloration.

Ongoing and future work including the investigation of the genetic mechanisms limiting the genetic correlation between sexes (e.g., sex-limited expression of autosomal genes can facilitate sexual dimorphism; Traut et al., 2007), quantifying costs and condition-dependence of sexually dimorphic traits and measuring natural and sexual selection in natural populations in the wood tiger moth system will continue to clarify the roles of both sexual and natural selection in the origins and maintenance of sexual dimorphism and male polymorphism.

\section{Components of Chemical Defenses Could Have a Dual Function in Predator Deterrence and Mate Attraction}

Recent developments concerning the chemical defenses of the wood tiger moth have revealed the presence of two methopyraxines (2-sec-butyl-3-methoxypyrazine and 2-isobutyl3-methoxypyrazine) that have a key role in predator deterrence (Rojas et al., 2017; Burdfield-Steel et al., 2018). By contrast, despite luring A. plantaginis males to pheromone traps during every field season, our knowledge of the compounds present in the pheromone blend(s) of A. plantaginis is only incipient (Muraki et al., 2017), with a number of microcompounds amongst the most prominent components. Pyrazines have been found in the pheromone blends of some insects, and seem to be particularly common in tiger moths (Rothschild et al., 1984; Guilford et al., 1987; Moore et al., 1990). Thus, we cannot dismiss the possibility that these methopyraxines, or some other compounds found in the prothoracic defensive fluids of these moths, have a dual role in protection from predators and mate attraction. Furthermore, we know that males 
transfer a spermatophore to females during mating (Chargé et al., 2016), but we currently do not know whether some protective chemicals, or any other type of nuptial gift, are also transmitted during this transfer.

Studies on the interaction between warning coloration and chemical defenses in the context of sexual selection are the next logical steps in studies on wood tiger moths. They are an excellent model to test these different components because it is possible to test the effect of each in isolation to understand its function and importance. The amount of both methoxypyrazines can be measured from individual moths, allowing detailed estimates of chemical defense level. With our increasing knowledge of the pheromones of this species we can begin to look for links between pheromone composition and chemical defense, and in particular, if the resource allocation patterns seen in coloration and defense (Furlanetto, 2017), extend to pheromone production. In that respect, it is also important to discover whether males produce pheromones, as is the case in some butterflies (Darragh et al., 2017) and other day-flying moths (Sarto I Monteys et al., 2016), and whether those are relevant for female choice/acceptance. If males do have pheromones, it would be key to examine whether there are additive effects of pheromone blend and hindwing color, or whether one signal is more important than the sum of both for mate attraction/choice. The same question could be addressed in the context of population divergence, for instance to understand if potential variation in the pheromone blends and chemical defenses link to the differences in coloration between the European and Caucasian populations.

\section{CURRENT KNOWLEDGE GAPS AND FUTURE DIRECTIONS}

As our review shows, previous studies have been focusing on understanding how sexual or natural selection (seldom both; Table 1, Figure 6C) could shape the evolution of warning coloration due to its multiple function as a signal of mate quality and possession of chemical defenses. Our review also highlights the need to study a greater variety of "non-model" species, such as the wood tiger moth. In particular, species that possess key components such as chemical or visual, may help fill critical gaps in our existing knowledge. We describe some of these gaps below, and propose some future avenues of study.

1. Studies exploring how natural versus sexual selection affect primary defenses are not abundant, but are on the rise. In contrast, with a few exceptions (e.g., studies on the dual role of pyrrolizine alkaloids in bella moths Utetheisa ornatrix; Conner et al., 1981), less effort has been made to test the possible multiple functions of chemical compounds in chemical communication between conspecifics and in predator deterrence. One potential chemical group with multiple functions could be pyrazines, a group of compounds that are relatively common in insect defensive fluids (Rothschild et al., 1984; Guilford et al., 1987; Moore et al., 1990; Vencl et al., 2016; Rojas et al., 2017). It is possible that, for example, the intensity of the repulsive odor produced by pyrazines could also function as an honest signal of quality. In those terms, a male with higher concentration of pyrazines could be better protected against predators, which in turn would inform females that he has the right condition to afford the costs of production or sequestration and thus make him more attractive as a mate. To our knowledge, this has been studied in detail only in, U. ornatrix (González et al., 1999; Iyengar and Starks, 2008); see section "Chemical Compounds Can Play a Role in Mate Attraction and Predator DeterrenceBut Could They Also Have a Dual Function?" above). Another way in which sexual and natural selection could act in synergy on chemical compounds is through the so-called nuptial gifts. A male could, for example, donate defensive chemicals to the female during mating to provide protection for the eggs or herself. In this type of situation the "odor" of the male could function both as a warning signal for predators and as a signal of mate quality for the females. Therefore, future research should consider the potential synergistic (or opposing) interactions between sexual selection and predation acting simultaneously on chemical and visual communication. We can start by investigating if the same compounds in the chemical defenses are also present in the pheromone blends, and how are they then potentially transferred to the spermatophores and eggs. We also need to test the relationship between the levels/types of defensive toxins a male possesses, combined with their attractiveness as a mate and their defensive coloration. Potentially good model organisms from which we already have information both on the influence of sexual and natural selection on different components of multimodal signals are listed in Table $\mathbf{1}$.

2. Defensive chemicals often evolve under multiple selection, protecting simultaneously from predators, pathogens, and parasitoids (Johnson Pieter et al., 2018). Many chemical compounds used in secondary defense or chemical communication can be sequestered directly from the diet or produced with the help of symbionts, which can alter the chemical profile of their hosts (Engl and Kaltenpoth, 2018). However, experimental evidence illustrating these interactions and their effect on host behaviors are still scarce. This is particularly true for symbionts involved in the production of insect pheromones (Engl and Kaltenpoth, 2018), thus providing a promising research avenue.

3. It is ideal to investigate the patterns of inheritance of the signals of interest. If the trait in question is not heritable, there are no grounds for natural selection to act on it (even if the trait is essential for survival). Likewise, we need to continue to study in depth how phenotypic variation exposed to selection by receivers is induced and maintained. To do that, we need to define the life-history costs of production and maintenance of different multimodal-signal components under various biotic and abiotic conditions (Hegna et al., 2013; Brain, 2016; Lindstedt et al., 2016). This will give us key information on how much of the signal variation is environmentally induced.

4. Before the role of any signal in either predator deterrence or mate attraction can be established, it is essential to identify and confirm the selective agent. Failure to properly do so can lead to misinterpretation or overestimation of the studied trait function. Chemical defenses, for example, may have very rich profiles with hundreds of compounds but, if relevant predators do not respond to them, then that defense is not under selection 
by predators. It is of curse possible that the relevant predator is no longer present and we are thus witnessing the consequence of past selection. Furthermore, we should keep in mind that selective agents fluctuate across time and space (e.g., Endler and Rojas, 2009; Nokelainen et al., 2014). This means, for example, that identifying a predator at a particular location does not imply it is a selective agent elsewhere.

5. An integrative study of multimodal signal evolution should involve a better understanding of how signals are processed by the receiver's sensory systems. Recent advances in the field of visual ecology (e.g., animal vision models; Vorobyev and Osorio, 1998; Kelber et al., 2003; Endler and Mielke, 2005; Maia et al., 2013; Kemp et al., 2015; Troscianko and Stevens, 2015; Renoult et al., 2017; Maia and White, 2018), as well as wellknown and widely used methods in chemical ecology (Harborne, 1997; Agelopoulos and Pickett, 1998) offer the tools to study if and how signals are discriminated against the background noise. However, knowing that a signal can be perceived is not enough. In addition to that, classic predation and mate choice experiments, particularly those in which the multiple components of the warning display can be tested in isolation and in different combinations, can provide information about the receiver's response. Whether or not receivers react to the signals sent by the emitter is what actually determines how these signals are shaped.

6. The role of behavior in aposematic displays has been largely understudied, although it has the potential to be, if not a signal, a relevant cue for predators in combination with other components. Evidence from studies on mimicry has highlighted how mimics fool predators by mimicking the motion type of their models. Such is the case of ant-mimicking spiders (genus Myrmarachne) of the family Salticidae, which are thought to mimic not only the morphology but also the characteristic movement of their ant models (Nelson and Card, 2016); or of certain species of hover flies (family Syrphidae), which mimic the behavior of wasps (Penney et al., 2014). While both the Myrmarachne spiders and the hover flies are Batesian (undefended) mimics, and thus not aposematic, they raise the question of whether aposematic species do also use behavior as a component of their warning displays. To date, we are aware of only one study in that direction: Neotropical aposematic butterflies can be told apart by bird predators from their nonaposematic counterparts on the basis of their flight behavior (Chai, 1986), and it cannot be discarded that it also plays a role in interactions between conspecifics, for example in courtship displays. Therefore, behavior in general, and motion in particular, combined with either warning colors or chemical defenses, may have a key function in predator deterrence and interactions between conspecifics in aposematic species.

7. Finally, the origin and spread of the first individuals bearing aposematic signals continues to be a matter of debate (Mappes et al., 2005; Speed and Ruxton, 2005). The first individuals with a conspicuous warning coloration would have been an easy target for predators, making it perplexing that they were able to multiply until they were numerous enough to prompt predator avoidance. One potential solution for this problem is that natural and sexual selection could both favor the evolution of aposematic displays, and one way to tackle it is using phylogenetic comparative methods. These methods have been used to study, for example, the correlated evolution of warning coloration and toxicity (Summers, 1987; Summers and Clough, 2001), but they would also be valuable to better understand how natural selection and sexual selection have jointly shaped the evolution of multimodal warning displays.

\section{AUTHOR CONTRIBUTIONS}

BR, JM, CL, SG, EB-S, KR, and ON conceived the scope of the review. $\mathrm{BR}, \mathrm{CD}$, and $\mathrm{LH}$ collected information from the literature. BR did the analyses and figures, and led the writing. All authors contributed to the discussion of ideas, writing and editing the manuscript, and approved the final version of it.

\section{ACKNOWLEDGMENTS}

We are most grateful to Astrid Groot and Varvara Vedenina for the invitation to contribute to this special issue, to two reviewers, for their constructive and encouraging feedback, and to Oskar Brattström, Susan Finkbeiner, Eduard Florin Niga, JP Lawrence, Paul Marek, Pablo Palacios, Andrius Pašukonis, Nicholas Scobel, and Ryan Taylor for kindly allowing us to use their photographs. Many thanks to Kaisa Suisto, Jimi Kirvesoja, and all the greenhouse workers at the University of Jyväskylä who have made it possible to keep a healthy moth stock; and to Helinä Nisu for her invaluable help with the birds used in some of the experiments mentioned here. We gratefully acknowledge funding from the Centre of Excellence in Biological interactions (Academy of Finland, project no. 284666 to JM). BR is particularly thankful to J. Stynoski and S. Calhim for ideas on data visualization. We also thank the Academy of Finland for the Post-Doctoral Fellow funding to ON (project no. 21000038821) and SG (project no. 21000027441).

\section{REFERENCES}

Adamova-Jezova, D., Hospodkova, E., Fuchsova, L., Stys, P., and Exnerova, A. (2016). Through experience to boldness? Deactivation of neophobia towards novel and aposematic prey in three European species of tits (Paridae). Behav. Process. 131, 24-31. doi: 10.1016/j.beproc.2016.07.014

Agelopoulos, N. G., and Pickett, J. A. (1998). Headspace analysis in chemical ecology: effects of different sampling methods on ratios of volatile

compounds present in headspace samples. J. Chem. Ecol. 24, 1161-1172. doi: 10.1023/A:1022442818196

Aliabadi, A., Renwick, J. A., and Whitman, D. W. (2002). Sequestration of glucosinolates by harlequin bug Murgantia histrionica. J. Chem. Ecol. 28, 1749-1762. doi: 10.1023/A:1020505016637

Allen, C. E., Zwaan, B. J., and Brakefield, P. M. (2010). Evolution of sexual dimorphism in the Lepidoptera. Annu. Rev. Entomol. 56, 445-464. doi: 10.1146/annurev-ento-120709-144828 
Aluthwattha, S. T., Harrison, R. D., Ranawana, K. B., Xu, C., Lai, R., and Chen, J. (2017). Does spatial variation in predation pressure modulate selection for aposematism? Ecol. Evol. 7, 7560-7572. doi: 10.1002/ece3.3221

Andersen, K. K., Bernstien, D. T., Caret, R. L., and Romanczyk, L. J. (1982). Chemical constituents of the defensive secretion of the striped skunk (Mephitis mephitis). Tetrahedron 38, 1965-1970. doi: 10.1016/0040-4020(82)80046-X

Ang, H. P., and Newman, L. J. (1998). Warning colouration in pseudocerotid flatworms (Platyhelminthes, Polycladida). A preliminary study. Hydrobiologia 383, 29-33. doi: 10.1023/A:1003449226586

Arias, M., Meichanetzoglou, A., Elias, M., Rosser, N., De-Silva, D. L., Nay, B., et al. (2016). Variation in cyanogenic compounds concentration within a Heliconius butterfly community: does mimicry explain everything? BMC Evol. Biol. 16:272. doi: $10.1186 /$ s12862-016-0843-5

Awad, M., Laugier, G. J. M., Loiseau, A., and Nedvěd, O. (2015). Unbalanced polyandry in wild-caught ladybirds Harmonia axyridis (Coleoptera: Coccinellidae). Appl. Entomol. Zool. 50, 427-434. doi: $10.1007 / \mathrm{s} 13355-015-0348-5$

Barber, J. R., Chadwell, B. A., Garrett, N., Schmidt-French, B., and Conner, W. E. (2009). Naive bats discriminate arctiid moth warning sounds but generalize their aposematic meaning. J. Exp. Biol. 212, 2141-2148. doi: 10.1242/jeb.029991

Barber, J. R., and Conner, W. E. (2007). Acoustic mimicry in a predatorprey interaction. Proc. Natl. Acad. Sci. U.S.A. 104, 9331-9334. doi: $10.1073 /$ pnas.0703627104

Benes, J., and Vesely, P. (2017). The ability of lizards to identify an artificial Batesian mimic. Zoology 123, 46-52. doi: 10.1016/j.zool.2017.05.010

Benson, W. W. (1972). Natural selection for Müllerian mimicry in Heliconius erato in Costa Rica. Science 176:936. doi: 10.1126/science.176.4037.936

Bezzerides, A. L., McGraw, K. J., Parker, R. S., and Husseini, J. (2007). Elytra color as a signal of chemical defense in the Asian ladybird beetle Harmonia axyridis. Behav. Ecol. Sociobiol. 61, 1401-1408. doi: 10.1007/s00265-007-0371-9

Bonacci, T., Aloise, G., Brandmayr, P., Brandmayr, T. Z., and Capula, M. (2008). Testing the predatory behaviour of Podarcis sicula (Reptilia : Lacertidae) towards aposematic and non-aposematic preys. Amphib. Reptil. 29, 449-453. doi: 10.1163/156853808785111986

Bonacci, T., Massolo, A., Brandmayr, P., and Brandmayr, T. Z. (2006). Predatory behaviour on ground beetles (Coleoptera : Carabidae) by Ocypus olens (Muller) (Coleoptera : Staphylinidae) under laboratory conditions. Entomol. News 117, 545-551. doi: 10.3157/0013-872X(2006)117[545:PBOGBC]2.0.CO;2

Boppré, M., Petty, R. L., Schneider, D., Meinwald, J. (1978). Behaviorally mediated contacts between scent organs: Another prerequisite for pheromone production in Danaus chrysippus males (lepidoptera). J. Comp. Physiol. 126, 97-103. doi: 10.1007/BF00666361

Borer, M., Van Noort, T., Rahier, M., and Naisbit, R. E. (2010). Positive frequencydependent selection on warning color in alpine leaf beetles Evolution 64, 3629-3633. doi: 10.1111/j.1558-5646.2010.01137.x

Bowers, M. D. (1992). "The evolution of unpalatability and the cost of chemical defense in insects," in Insect Chemical Ecology. An Evolutionary Approach, eds B. D. Roitberg and M. B. Isman (London: Chapman \& Hall), 216-244.

Bradbury, J. W., and Vehrencamp, S. L. (2011). Principles of Animal Communication. Sunderland, MA: Sinauer Associates Inc.

Brain, M. A. (2016). Can Warning Signals Be Honest? Wing Colouration and the Strength of Chemical Defence in the Female Wood Tiger Moth. University of Jyväskylä.

Brodie, E. D., and Janzen, F. J. (1995). Experimental studies of coral snake mimicry - generalized avoidance of ringed snake patterns by free-ranging avian predators. Funct. Ecol. 9, 186-190. doi: 10.2307/2390563

Brown, J. L., Maan, M. E., Cummings, M. E., and Summers, K. (2010). Evidence for selection on coloration in a Panamanian poison frog: a coalescent-based approach. J. Biogeogr. 37, 891-901. doi: 10.1111/j.1365-2699.2009.02260.x

Brown, Jr, K. S. (1984). Adult-obtained pyrrolizidine alkaloids defend ithomiine butterflies against a spider predator. Nature 309, 707.

Buasso, C. M., Leynaud, G. C., and Cruz, F. B. (2006). Predation on snakes of Argentina: effects of coloration and ring pattern on coral and false coral snakes. Stud. Neotrop. Fauna Environ. 41, 183-188. doi: 10.1080/01650520600630725

Burdfield-Steel, E., Pakkanen, H., Rojas, B., Galarza, J. A., and Mappes, J. (2018). De novo synthesis of chemical defenses in an aposematic moth. J. Insect Sci. 18:28. doi: $10.1093 /$ jisesa/iey020
Burdfield-Steel, E. R., Dougherty, L. R., Smith, L. A., Collins, L. A., and Shuker, D. M. (2013). Variation in social and sexual behaviour in four species of aposematic seed bugs (Hemiptera: Lygaeidae): the role of toxic and non-toxic food. Behav. Process. 99, 52-61. doi: 10.1016/j.beproc.2013.06.006

Cardoso, M. Z. (1997). Testing chemical defence based on pyrrolizidine alkaloids. Anim. Behav. 54, 985-991. doi: 10.1006/anbe.1997.0505

Cardoso, M. Z., and Gilbert, L. E. (2013). Pollen feeding, resource allocation and the evolution of chemical defence in passion vine butterflies. J. Evol. Biol. 26, 1254-1260. doi: 10.1111/jeb.12119

Casas-Cardona, S., Marquez, R., and Vargas-Salinas, F. (2018). Different colour morphs of the poison frog Andinobates bombetes (Dendrobatidae) are similarly effective visual predator deterrents. Ethology 124, 245-255. doi: 10.1111/eth.12729

Castillo-Guevara, C., and Rico-Gray, V. (2002). Is cycasin in Eumaeus minyas (Lepiodoptera : Lycaenidae) a predator deterrent? Interciencia 27, 465-470.

Chai, P. (1986). Field observations and feeding experiments on the responses of Rufous-tailed jacamars (Galbula ruficauda) to free-flying butterflies in a tropical rainforest. Biol. J. Linn. Soc. 29, 161-189. doi: 10.1111/j.1095-8312.1986.tb01772.x

Chargé, R., Wedell, N., Lindstedt, C., Hämäläinen, L., Övermark, E., and Mappes, J. (2016). Variation in male fertility in a polymorphic moth, Parasemia plantaginis. Anim. Behav. 111, 33-40. doi: 10.1016/j.anbehav.2015.10.014

Chouteau, M., and Angers, B. (2011). The role of predators in maintaining the geographic organization of aposematic signals. Am. Nat. 178, 810-817. doi: $10.1086 / 662667$

Chouteau, M., Arias, M., and Joron, M. (2016). Warning signals are under positive frequency-dependent selection in nature. Proc. Natl. Acad. Sci. U.S.A. 113, 2164-2169. doi: 10.1073/pnas.1519216113

Chouteau, M., Llaurens, V., Piron-Prunier, F., and Joron, M. (2017). Polymorphism at a mimicry supergene maintained by opposing frequencydependent selection pressures. Proc. Natl. Acad. Sci. U.S.A. 114, 8325-8329. doi: $10.1073 /$ pnas.1702482114

Codella, S. G., and Lederhouse, R. C. (1990). The effect of wing orientation on aposematic signaling in the pipevine swallowtail butterfly, Battus philenor. Anim. Behav. 40, 404-406. doi: 10.1016/S0003-3472(05)8 0938-8

Comeault, A. A., and Noonan, B. P. (2011). Spatial variation in the fitness of divergent aposematic phenotypes of the poison frog, Dendrobates tinctorius. J. Evol. Biol. 24, 1374-1379. doi: 10.1111/j.1420-9101.2011.02258.x

Conner, W. E., Eisner, T., Vander Meer, R. K., Guerrero, A., and Meinwald, J. (1981). Precopulatory sexual interaction in an arctiid moth (Utetheisa ornatrix): role of a pheromone derived from dietary alkaloids. Behav. Ecol. Sociobiol. 9, 227-235. doi: 10.1007/BF00302942

Cortesi, F., and Cheney, K. L. (2010). Conspicuousness is correlated with toxicity in marine opisthobranchs. J. Evol. Biol. 23, 1509-1518. doi: 10.1111/j.1420-9101.2010.02018.x

Cott, H. B. (1940). Adaptive Colouration in Animals. London: Methuen.

Crothers, L., Gering, E., and Cummings, M. (2011). Aposematic signal variation predicts male-male interactions in a polymorphic poison frog Evolution 65, 599-605. doi: 10.1111/j.1558-5646.2010.01154.x

Crothers, L. R., and Cummings, M. E. (2015). A multifunctional warning signal behaves as an agonistic status signal in a poison frog. Behav. Ecol. 26, 560-568. doi: 10.1093/beheco/aru231

Cummings, M. E., and Crothers, L. R. (2013). Interacting selection diversifies warning signals in a polytypic frog: an examination with the strawberry poison frog. Evol. Ecol. 27, 693-710. doi: 10.1007/s10682-013-9648-9

Darragh, K., Vanjari, S., Mann, F., Gonzalez-Rojas, M. F., Morrison, C. R., Salazar, C., et al. (2017). Male sex pheromone components in Heliconius butterflies released by the androconia affect female choice. PeerJ 5:e3953. doi: $10.7717 /$ peerj.3953

Darst, C. R., Cummings, M. E., and Cannatella, D. C. (2006). A mechanism for diversity in warning signals: conspicuousness versus toxicity in poison frogs. Proc. Natl. Acad. Sci. U.S.A. 103:5852. doi: 10.1073/pnas.06006 25103

Darwin, C. R. (1869). On the Origin of Species by Means of Natural Selection, or the Preservation of Favoured Races in the Struggle for Life. London: John Murray. 
Dell'aglio, D. D., Stevens, M., and Jiggins, C. D. (2016). Avoidance of an aposematically coloured butterfly by wild birds in a tropical forest. Ecol. Entomol. 41, 627-632. doi: 10.1111/een.12335

Dolenska, M., Nedved, O., Vesely, P., Tesarova, M., and Fuchs, R. (2009). What constitutes optical warning signals of ladybirds (Coleoptera: Coccinellidae) towards bird predators: colour, pattern or general look? Biol. J. Linn. Soc. 98, 234-242. doi: 10.1111/j.1095-8312.2009.01277.x

Dreher, C. E., and Pröhl, H. (2014). Multiple sexual signals: calls over colors for mate attraction in an aposematic, color-diverse poison frog. Front. Ecol. Evol. 2:22. doi: $10.3389 /$ fevo.2014.00022

Dunning, D. C., Acharya, L., Merriman, C. B., and Dalferro, L. (1992). Interactions between bats and arctiid moths. Can. J. Zool. 70, 2218-2223. doi: $10.1139 / \mathrm{z} 92-298$

Dunning, D. C., and Kruger, M. (1995). Aposematic sounds in african moths. Biotropica 27, 227-231. doi: 10.2307/2388998

Dunning, D. C., and Kruger, M. (1996). Predation upon moths by free-foraging Hipposideros caffer. J. Mammal. 77, 708-715. doi: 10.2307/1382675

Edmunds, M. (1974). Defence in Animals: A Survey of Antipredator Defences. New York, NY: Longman.

Eisner, T., Schroeder, F. C., Snyder, N., Grant, J. B., Aneshansley, D. J., Utterback, D., et al. (2008). Defensive chemistry of lycid beetles and of mimetic cerambycid beetles that feed on them. Chemoecology 18, 109-119. doi: 10.1007/s00049-007-0398-4

Eisner, T., Smedley, S. R., Young, D. K., Eisner, M., Roach, B., and Meinwald, J. (1996a). Chemical basis of courtship in a beetle (Neopyrochroa flabellata): cantharidin as "nuptial gift". Proc. Natl. Acad. Sci. U.S.A. 93, 6499-6503. doi: $10.1073 /$ pnas.93.13.6499

Eisner, T., Smedley, S. R., Young, D. K., Eisner, M., Roach, B., and Meinwald, J. (1996b). Chemical basis of courtship in a beetle (Neopyrochroa flabellata): cantharidin as precopulatory "enticing" agent. Proc. Natl. Acad. Sci. U.S.A. 93:6494. doi: 10.1073/pnas.93.13.6494

Endler, J. A. (1988a). Frequency-dependent predation, crypsis and aposematic coloration. Philos. Trans. R. Soc. Lond. Ser. B Biol. Sci. 319, 505-523. doi: 10.1098/rstb.1988.0062

Endler, J. A. (1988b). Sexual selection and predation risk in guppies. Nature 332, 593-594. doi: 10.1038/332593b0

Endler, J. A. (1992). Signals, signal condition and the direction of evolution. Am. Nat. 139, S125-S153. doi: 10.1086/285308

Endler, J. A., and Mappes, J. (2004). Predator mixes and the conspicuousness of aposematic signals. Am. Nat. 163, 532-547. doi: 10.1086/382662

Endler, J. A., and Mielke, P. W. (2005). Comparing entire colour patterns as birds see them. Biol. J. Linn. Soc. 86, 405-431. doi: 10.1111/j.1095-8312.2005.00 540. $\mathrm{x}$

Endler, J. A., and Rojas, B. (2009). The spatial pattern of natural selection when selection depends on experience. Am. Nat. 173, E62-E78. doi: 10.1086/596528

Engl, T., and Kaltenpoth, M. (2018). Influence of microbial symbionts on insect pheromones. Nat. Prod. Rep. 35, 386-397. doi: 10.1039/C7NP00068E

Estrada, C., and Jiggins, C. D. (2008). Interspecific sexual attraction because of convergence in warning colouration: is there a conflict between natural and sexual selection in mimetic species? J. Evol. Biol. 21, 749-760. doi: 10.1111/j.1420-9101.2008.01517.x

Exnerová, A., Jezová, D., Stys, P., Doktorovová, L., Rojas, B., and Mappes, J. (2015). Different reactions to aposematic prey in 2 geographically distant populations of great tits. Behav. Ecol. 26, 1361-1370. doi: 10.1093/beheco/ arv086

Exnerová, A., Svadová, K., Stys, P., Barcalová, S., Landová, E., Prokopová, M., et al. (2006). Importance of colour in the reaction of passerine predators to aposematic prey: experiments with mutants of Pyrrhocoris apterus (Heteroptera). Biol. J. Linn. Soc. 88, 143-153. doi: 10.1111/j.1095-8312.2006.00611.x

Finkbeiner, S. D., Briscoe, A., and Reed, R. D. (2014). Warning signals are seductive: relative contributions of color and pattern to predator avoidance and mate attraction in Heliconius butterflies. Evolution 68, 3410-3420. doi: $10.1111 /$ evo.12524

Fisher, R. A. (1930). The Genetical Theory of Natural Selection. Oxford: Oxford University Press.

Furlanetto, M. (2017). Investigating the Costs of Visual Signals and Chemical Defences in Arctia plantaginis. MSc Thesis, University of Padova.
Gade, M. R., Hill, M., and Saporito, R. A. (2016). Color assortative mating in a mainland population of the poison frog Oophaga pumilio. Ethology 122, 851-858. doi: 10.1111/eth.12533

Galarza, J. A., Nokelainen, O., Ashrafi, R., Hegna, R. H., and Mappes, J. (2014). Temporal relationship between genetic and warning signal variation in the aposematic wood tiger moth (Parasemia plantaginis). Mol. Ecol. 23, 4939-4957. doi: 10.1111/mec.12913

Geiselhardt, S., Otte, T., and Hilker, M. (2012). Looking for a similar partner: host plants shape mating preferences of herbivorous insects by altering their contact pheromones. Ecol. Lett. 15, 971-977. doi: 10.1111/j.1461-0248.2012.01816.x

Gimenez-Casalduero, F., Thacker, R. W., and Paul, V. J. (1999). Association of color and feeding deterrence by tropical reef fishes. Chemoecology 9, 33-39. doi: $10.1007 / \mathrm{s} 000490050031$

Gohli, J., and Hogstedt, G. (2009). Explaining the evolution of warning coloration: secreted secondary defence chemicals may facilitate the evolution of visual aposematic signals. PLoS ONE 4:e5779. doi: 10.1371/journal.pone.0005779

González, A., Rossini, C., Eisner, M., and Eisner, T. (1999). Sexually transmitted chemical defense in a moth Utetheisa ornatrix. Proc. Natl. Acad. Sci. U.S.A. 96:5570. doi: 10.1073/pnas.96.10.5570

Gordon, S. P., Kokko, H., Rojas, B., Nokelainen, O., and Mappes, J. (2015). Colour polymorphism torn apart by opposing positive frequencydependent selection, yet maintained in space. J. Anim. Ecol. 84, 1555-1564. doi: 10.1111/1365-2656.12416

Groeters, F. R., and Strong, K. L. (1993). Observations on distastefulness of Monistria concinna (Walker) (Orthoptera, Pyrgomorphidae). J. Austr. Entomol. Soc. 32, 153-154. doi: 10.1111/j.1440-6055.1993.tb00564.x

Groot, A. T., Horovitz, J. L., Hamilton, J., Santangelo, R. G., Schal, C., and Gould, F. (2006). Experimental evidence for interspecific directional selection on moth pheromone communication. Proc. Natl. Acad. Sci. U.S.A. 103:5858. doi: 10.1073/pnas.0508609103

Groot, A. T., Inglis, O., Bowdridge, S., Santangelo, R. G., Blanco, C., Juan, D., et al. (2009). Geographic and temporal variation in moth chemical communication. Evolution 63, 1987-2003. doi: 10.1111/j.1558-5646.2009.00702.x

Guilford, T., Nicol, C., Rothschild, M., and Moore, B. P. (1987). The biological roles of pyrazines: evidence for a warning odour function. Biol. J. Linn. Soc. 31, 113-128. doi: 10.1111/j.1095-8312.1987.tb01984.x

Haber, M., Cerfeda, S., Carbone, M., Calado, G., Gaspar, H., Neves, R., et al. (2010). Coloration and defense in the nudibranch gastropod Hypselodoris fontandraui. Biol. Bull. 218, 181-188. doi: 10.1086/BBLv218n2p181

Hämäläinen, L., Valkonen, J., Mappes, J., and Rojas, B. (2015). Visual illusions in predator-prey interactions: birds find moving patterned prey harder to catch. Anim. Cogn. 18, 1059-1068. doi: 10.1007/s10071-015-0874-0

Harborne, J. B. (1997). Recent advances in chemical ecology. Nat. Prod. Rep. 14, 83-98. doi: 10.1039/np9971400083

Härlin, C., and Härlin, M. (2003). Towards a historization of aposematism. Evol. Ecol. 17, 197-212. doi: 10.1023/A:1023047930360

Hatle, J. D., and Faragher, S. G. (1998). Slow movement increases the survivorship of a chemically defended grasshopper in predatory encounters. Oecologia 115, 260-267. doi: 10.1007/s004420050515

Heath, R. R., Mclaughlin, J. R., Proshold, F., and Teal, P. E. A. (1991). Periodicity of female sex pheromone titer and release in Heliothis subflexa and $H$. virescens (Lepidoptera: Noctuidae). Ann. Entomol. Soc. Am. 84, 182-189. doi: 10.1093/aesa/84.2.182

Hebets, E. A., and Papaj, D. R. (2005). Complex signal function: developing a framework of testable hypotheses. Behav. Ecol. Sociobiol. 57, 197-214. doi: 10.1007/s00265-004-0865-7

Hegna, R. H., Galarza, J. A., and Mappes, J. (2015). Global phylogeography and geographical variation in warning coloration of the wood tiger moth (Parasemia plantaginis). J. Biogeogr. 42, 1469-1481. doi: 10.1111/jbi.12513

Hegna, R. H., and Mappes, J. (2014). Influences of geographic differentiation in the forewing warning signal of the wood tiger moth in Alaska. Evol. Ecol. 28, 1003-1017. doi: 10.1007/s10682-014-9734-7

Hegna, R. H., Saporito, R. A., and Donnelly, M. A. (2013). Not all colors are equal: predation and color polytypism in the aposematic poison frog Oophaga pumilio. Evol. Ecol. 27, 831-845. doi: 10.1007/s10682-012-9605-z

Hegna, R. H., Saporito, R. A., Gerow, K. G., and Donnelly, M. A. (2011). Contrasting colors of an aposematic poison frog do not affect predation. Ann. Zool. Fenn. 48, 29-38. doi: 10.5735/086.048.0103 
Henze, M., Lind, O., Mappes, J., Rojas, B., and Kelber, A. (2018). An aposematic colour-polymorphic moth seen through the eyes of conspecifics and predators - sensitivity and colour discrimination in a tiger moth. Funct. Ecol. doi: 10.1111/1365-2435.13100. [Epub ahead of print].

Higham, J. P., and Hebets, E. A. (2013). An introduction to multimodal communication. Behav. Ecol. Sociobiol. 67, 1381-1388. doi: 10.1007/s00265-013-1590-x

Honma, A., Mappes, J., and Valkonen, J. K. (2015). Warning coloration can be disruptive: aposematic marginal wing patterning in the wood tiger moth. Ecol. Evol. 5, 4863-4874. doi: 10.1002/ece3.1736

Hristov, N., and Conner, W. E. (2005). Effectiveness of tiger moth (Lepidoptera, Arctiidae) chemical defenses against an insectivorous bat (Eptesicus fuscus). Chemoecology 15, 105-113. doi: 10.1007/s00049-005-0301-0

Hunter, J. S. (2009). Familiarity breeds contempt: effects of striped skunk color, shape, and abundance on wild carnivore behavior. Behav. Ecol. 20, 1315-1322. doi: 10.1093/beheco/arp144

Ingalls, V. (1993). Startle and habituation responses of blue jays (Cyanocitta cristata) in a laboratory simulation of antipredator defenses of catocala moths (Lepidoptera, Noctuidae). Behaviour 126, 77-96. doi: 10.1163/156853993X00353

Ingleby, F. C. (2015). Insect cuticular hydrocarbons as dynamic traits in sexual communication. Insects 6, 732-742. doi: 10.3390/insects6030732

Iyengar, V. K., and Starks, B. D. (2008). Sexual selection in harems: male competition plays a larger role than female choice in an amphipod. Behav. Ecol. 19, 642-649. doi: 10.1093/beheco/arn009

Jiggins, C. D. (2017). The Ecology and Evolution of Heliconius Butterflies. Oxford: Oxford University Press.

Jiggins, C. D., Naisbit, R. E., Coe, R. L., and Mallet, J. (2001). Reproductive isolation caused by colour pattern mimicry. Nature 411, 302-305. doi: 10.1038/35077075

Johansen, A. I., Exnerová, A., Svadová, K. H., Stys, P., Gamberale-Stille, G., and Tullberg, B. S. (2010). Adaptive change in protective coloration in adult striated shieldbugs Graphosoma lineatum (Heteroptera: Pentatomidae): test of detectability of two colour forms by avian predators. Ecol. Entomol. 35, 602-610. doi: 10.1111/j.1365-2311.2010.01219.x

Johnson Pieter, T. J., Calhoun Dana, M., Stokes Amber, N., Susbilla Calvin, B., McDevitt-Galles, T., Briggs Cheryl, J., et al. (2018). Of poisons and parasitesthe defensive role of tetrodotoxin against infections in newts. J. Anim. Ecol. 87, 1192-1204. doi: 10.1111/1365-2656.12816

Joron, M., and Mallet, J. (1998). Diversity in mimicry: paradox or paradigm? . Trends Ecol. Evol. 13, 461-463. doi: 10.1016/S0169-5347(98)01483-9

Kang, C. K., Lee, S. I., and Jablonski, P. G. (2011). Effect of sex and bright coloration on survival and predator-induced wing damage in an aposematic lantern fly with startle display. Ecol. Entomol. 36, 709-716. doi: 10.1111/j.1365-2311.2011.01319.x

Kauppinen, J., and Mappes, J. (2003). Why are wasps so intimidating: field experiments on hunting dragonflies (Odonata: Aeshna grandis). Anim. Behav. 66, 505-511. doi: 10.1006/anbe.2003.2225

Kelber, A., Vorobyev, M., and Osorio, D. (2003). Animal colour vision - behavioural tests and physiological concepts. Biol. Rev. 78, 81-118. doi: $10.1017 /$ S1464793102005985

Kemp, D. J., Herberstein, M. E., Fleishman, L. J., Endler, J. A., Bennett, A. T. D., Dyer, A. G., et al. (2015). An integrative framework for the appraisal of coloration in nature. Am. Nat. 185, 705-724. doi: 10.1086/ 681021

Kim, Y. H., Brown, G. B., and Mosher, H. S. (1975). Tetrodotoxin: occurrence in atelopid frogs of Costa Rica. Science 189, 151-152. doi: 10.1126/science.1138374

Kirchner, W. H., and Roschard, J. (1999). Hissing in bumblebees: an interspecific defence signal. Insectes Soc. 46, 239-243. doi: 10.1007/s0004000 50140

Klun, J. A., Plimmer, J. R., Bierl-Leonhardt, B. A., Sparks, A. N., Primiani, M., Chapman, O. L., et al. (1980). Sex pheromone chemistry of female corn earworm moth, Heliothis zea. Chem. Ecol. 6, 165-175. doi: 10.1007/BF00987535

Kotiaho, J., Alatalo Rauno, V., Mappes, J., Parri, S., and Rivero, A. (1998). Male mating success and risk of predation in a wolf spider: a balance between sexual and natural selection? J. Anim. Ecol. 67, 287-291. doi: 10.1046/j.1365-2656.1998.00192.x
Krall, B. S., Bartelt, R. J., Lewis, C. J., and Whitman, D. W. (1999). Chemical defense in the stink bug Cosmopepla bimaculata. J. Chem. Ecol. 25, 2477-2494. doi: 10.1023/A:1020822107806

Kuchta, S. R. (2005). Experimental support for aposematic coloration in the salamander Ensatina eschscholtzii xanthoptica: implications for mimicry of Pacific Newts. Copeia 2005, 265-271. doi: 10.1643/CH-04-173R

Kunte, K. (2008). Mimetic butterflies support Wallace's model of sexual dimorphism. Proc. R. Soc. B Biol. Sci. 275, 1617-1624. doi: $10.1098 /$ rspb.2008.0171

Landová, E., Svadová, K. H., Fuchs, R., Stys, P., and Exnerová, A. (2017). The effect of social learning on avoidance of aposematic prey in juvenile great tits (Parus major). Anim. Cogn. 20, 855-866. doi: 10.1007/s10071-017-1106-6

Langham, G. M. (2004). Specialized avian predators repeatedly attack novel color morphs of Heliconius butterflies. Evolution 58, 2783-2787. doi: 10.1111/j.0014-3820.2004.tb01629.x

Lanier, G. N., Classon, A., Stewart, T., Piston, J. J., and Silverstein, R. M. (1980). IPS pini: the basis for interpopulational differences in pheromone biology. J. Chem. Ecol. 6, 677-687. doi: 10.1007/BF00987678

Lartviere, S., and Messier, F. (1996). Aposematic behaviour in the striped skunk, Mephitis mephitis. Ethology 102, 986-992. doi: 10.1111/j.1439-0310.1996.tb01176.x

Lawrence, J. P., Mahony, M., and Noonan, B. P. (2018). Differential responses of avian and mammalian predators to phenotypic variation in Australian Brood Frogs. PLoS ONE 13:e195446. doi: 10.1371/journal.pone.0195446

Lindstedt, C., Boncoraglio, G., Cotter, S., Gilbert, J., and Kilner, R. M. (2017). Aposematism in the burying beetle? Dual function of anal fluid in parental care and chemical defense. Behav. Ecol. 28, 1414-1422. doi: 10.1093/beheco/arx100

Lindstedt, C., Eager, H., Ihalainen, E., Kahilainen, A., Stevens, M., and Mappes, J. (2011). Direction and strength of selection by predators for the color of the aposematic wood tiger moth. Behav. Ecol. 22, 580-587. doi: 10.1093/beheco/arr017

Lindstedt, C., Schroderus, E., Lindström, L., Mappes, T., and Mappes, J. (2016). Evolutionary constraints of warning signals: a genetic trade-off between the efficacy of larval and adult warning coloration can maintain variation in signal expression. Evolution 70, 2562-2672. doi: 10.1111/evo.13066

Lindstedt, C., Talsma, J. H. R., Ihalainen, E., Lindstrom, L., and Mappes, J. (2010). Diet quality affects warning coloration indirectly: excretion costs in a generalist herbivore. Evolution 64, 68-78. doi: 10.1111/j.1558-5646.2009.00796.x

Lindström, L., Ahtiainen, J. J., Mappes, J., Kotiaho, J. S., Lyytinen, A., and Alatalo, R. V. (2005). Negatively condition dependent predation cost of a positively condition dependent sexual signalling. J. Evol. Biol. 19, 649-656. doi: 10.1111/j.1420-9101.2005.01043.x

Lindström, L., Alatalo, R. V., Lyytinen, A., and Mappes, J. (2001). Strong antiapostatic selection against novel rare aposematic prey. Proc. Natl. Acad. Sci. U.S.A. 98, 9181-9184. doi: 10.1073/pnas.161071598

Long, E. C., Hahn, T. P., and Shapiro, A. M. (2014). Variation in wing pattern and palatability in a female-limited polymorphic mimicry system. Ecol. Evol. 4, 4543-4552. doi: 10.1002/ece3.1308

Lyytinen, A., Brakefield, P. M., Lindström, L., and Mappes, J. (2004). Does predation maintain eyespot plasticity in Bicyclus anynana? Proc. R. Soc. Lond. Ser. B Biol. Sci. 271:279. doi: 10.1098/rspb.2003.2571

Maan, M. E., and Cummings, M. E. (2008). Female preferences for aposematic signal components in a polymorphic poison frog. Evolution 62, 2334-2345. doi: 10.1111/j.1558-5646.2008.00454.x

Maan, M. E., and Cummings, M. E. (2009). Sexual dimorphism and directional sexual selection on aposematic signals in a poison frog. Proc. Natl. Acad. Sci. U.S.A. 106, 19072-19077. doi: 10.1073/pnas.0903327106

Maan, M. E., and Cummings, M. E. (2012). Poison frog colors are honest signals of toxicity, particularly for bird predators. Am. Nat. 179, E1-E14. doi: $10.1086 / 663197$

Maan, M. E., and Seehausen, O. (2011). Ecology, sexual selection and speciation. Ecol. Lett. 14, 591-602. doi: 10.1111/j.1461-0248.2011.01606.x

Maia, R., Eliason, C. M., Bitton, P.-P., Doucet, S. M., and Shawkey, M. D. (2013). pavo: an R package for the analysis, visualization and organization of spectral data. Methods Ecol. Evol. 4, 906-913. doi: 10.1111/2041-210X.12069

Maia, R., and White, T. E. (2018). Comparing colors using visual models. Behav. Ecol. 29, 649-659. doi: 10.1093/beheco/ary017 
Majerus, M., Odonald, P., and Weir, J. (1982). Evidence for preferential mating in Adalia bipunctata. Heredity 49, 37-49. doi: 10.1038/hdy.1982.63

Mallet, J. (2007). Hybrid speciation. Nature 446:279. doi: 10.1038/nature05706

Mallet, J. (2010). Shift happens! Shifting balance and the evolution of diversity in warning colour and mimicry. Ecol. Entomol. 35, 90-104. doi: 10.1111/j.1365-2311.2009.01137.x

Mallet, J., and Barton, N. H. (1989). Strong natural selection in a warning-color hybrid zone. Evolution 43, 421-431. doi: 10.1111/j.1558-5646.1989.tb04237.x

Mallet, J., and Joron, M. (1999). Evolution of diversity in warning color and mimicry: polymorphisms, shifting balance, and speciation. Annu. Rev. Ecol. Syst. 30, 201-233. doi: 10.1146/annurev.ecolsys.30.1.201

Mallet, J., and Singer, M. C. (1987). Individual selection, kin selection, and the shifting balance in the evolution of warning colours: the evidence from butterflies. Biol. J. Linn. Soc. 32, 337-350. doi: 10.1111/j.1095-8312.1987.tb00435.x

Mappes, J., Marples, N., and Endler, J. A. (2005). The complex business of survival by aposematism. Trends Ecol. Evol. 20, 598-603. doi: 10.1016/j.tree.2005.07.011

Marek, P., Papaj, D., Yeager, J., Molina, S., and Moore, W. (2011). Bioluminescent aposematism in millipedes. Curr. Biol. 21, R680-R681. doi: 10.1016/j.cub.2011.08.012

Marples, N. M., Vanveelen, W., and Brakefield, P. M. (1994). The relative importance of color, taste and smell in the protection of an aposematic insect Coccinella septempunctata. Anim. Behav. 48, 967-974. doi: $10.1006 /$ anbe.1994.1322

Martinez-Freiria, F., De Lanuza, G. P. I., Pimenta, A. A., Pinto, T., and Santos, X. (2017). Aposematism and crypsis are not enough to explain dorsal polymorphism in the Iberian adder. Acta Oecol. Int. J. Ecol. 85, 165-173. doi: 10.1016/j.actao.2017.11.003

Mavárez, J., Salazar, C. A., Bermingham, E., Salcedo, C., Jiggins, C. D., and Linares, M. (2006). Speciation by hybridization in Heliconius butterflies. Nature 441:868. doi: 10.1038 /nature 04738

Maynard Smith, J., and Harper, D. G. C. (2003). Animal Signals. Oxford: Oxford University Press.

Mayr, E. (1963). Animal Species and Evolution. Cambridge: Harvard University Press.

Medina, I., Wang, I. J., Salazar, C., and Amézquita, A. (2013). Hybridization promotes color polymorphism in the aposematic harlequin poison frog, Oophaga histrionica. Ecol. Evol. 3, 4388-4400. doi: 10.1002/ece3.794

Meredith, T. L., Cowart, J. D., Henkel, T. P., and Pawlik, J. R. (2007). The polychaete Cirriformia punctata is chemically defended against generalist coral reef predators. J. Exp. Mar. Biol. Ecol. 353, 198-202. doi: 10.1016/j.jembe.2007.08.023

Mérot, C., Frérot, B., Leppik, E., and Joron, M. (2015). Beyond magic traits: multimodal mating cues in Heliconius butterflies. Evolution 69, 2891-2904. doi: 10.1111/evo.12789

Merrill, R., Dasmahapatra, K., Davey, J., Dell'aglio, D., Hanly, J., Huber, B., et al. (2015). The diversification of Heliconius butterflies: what have we learned in 150 years? J. Evol. Biol. 28, 1417-1438. doi: 10.1111/jeb.12672

Merrill Richard, M., Chia, A., and Nadeau Nicola, J. (2014). Divergent warning patterns contribute to assortative mating between incipient Heliconius species. Ecol. Evol. 4, 911-917. doi: 10.1002/ece3.996

Merrill, R. M., Wallbank, R. W. R., Bull, V., Salazar, P. C. A., Mallet, J., Stevens, M., et al. (2012). Disruptive ecological selection on a mating cue. Proc. R. Soc. B Biol. Sci. 279:4907. doi: 10.1098/rspb.2012.1968

Mochida, K. (2011). Combination of local selection pressures drives diversity in aposematic signals. Evol. Ecol. 25, 1017-1028. doi: 10.1007/s10682-0119471-0

Moore, B. P., Brown, W. V., and Rothschild, M. (1990). Methylalkylpyrazines in aposematic insects, their hostplants and mimics. Chemoecology 1, 43-51. doi: $10.1007 / \mathrm{BF} 01325227$

Moore, C. D., and Hassall, C. (2016). A bee or not a bee: an experimental test of acoustic mimicry by hoverflies. Behav. Ecol. 27, 1767-1774. doi: 10.1093/beheco/arw107

Moosman, P. R., Cratsley, C. K., Lehto, S. D., and Thomas, H. H. (2009). Do courtship flashes of fireflies (Coleoptera: Lampyridae) serve as aposematic signals to insectivorous bats? Anim. Behav. 78, 1019-1025. doi: 10.1016/j.anbehav.2009.07.028
Mosher, H. S., Fuhrman, F. A., Buchwald, H. D., and Fischer, H. G. (1964) Tarichatoxin-Tetrodotoxin: a potent neurotoxin. Science 144, 1100-1110. doi: $10.1126 /$ science. 144.3622 .1100

Müller, F. (1879). Ituna and Thyridia: a remarkable case of mimicry in butterflies. Trans. Entomol. Soc. Lond. 1879, 20-29.

Muraki, Y., Yamakawa, R., Yamamoto, M., Naka, H., Honma, A., Mappes, J., et al. (2017). GC/FT-IR Analysis of novel 4,6,9-Triene and 2,4,6,9-Tetraene occurring in a female pheromone gland of Arctia plantaginis (Erebidae: Arctiinae). Am. J. Anal. Chem. 8, 645-656. doi: 10.4236/ajac.2017.810047

Nahrstedt, A., and Davis, R. H. (1983). Occurrence, variation and biosynthesis of the cyanogenic glucosides linamarin and lotaustralin in species of the Heliconiini (Insecta: Lepidoptera). Compar. Biochem. Physiol. Part B 75, 65-73. doi: 10.1016/0305-0491(83)90041-X

Nelson, X. J., and Card, A. (2016). Locomotory mimicry in ant-like spiders. Behav. Ecol. 27, 700-707. doi: 10.1093/beheco/arv218

Newcombe, D., Blount Jonathan, D., Mitchell, C., and Moore Allen, J. (2013). Chemical egg defence in the large milkweed bug, Oncopeltus fasciatus, derives from maternal but not paternal diet. Entomol. Exp. Appl. 149, 197-205. doi: 10.1111/eea.12128

Niskanen, M., and Mappes, J. (2005). Significance of the dorsal zigzag pattern of Vipera latastei gaditana against avian predators. J. Anim. Ecol. 74, 1091-1101. doi: 10.1111/j.1365-2656.2005.01008.x

Noboa, V., and Gillette, R. (2013). Selective prey avoidance learning in the predatory sea slug Pleurobranchaea californica. J. Exp. Biol. 216, 3231-3236. doi: $10.1242 / \mathrm{jeb} .079384$

Noge, K., Prudic, K. L., and Becerra, J. X. (2012). Defensive roles of (E)-2Alkenals and related compounds in Heteroptera. J. Chem. Ecol. 38, 1050-1056. doi: 10.1007/s10886-012-0166-y

Nokelainen, O. (2013). Many forms of the wood tiger moth (Parasemia plantaginis): selective heterogeneity favours polymorphic warning signals. Jyväskylä Stud. Biol. Environment. Sci. 259, 1-52.

Nokelainen, O., Hegna, R. H., Reudler, J. H., Lindstedt, C., and Mappes, J. (2012). Trade-off between warning signal efficacy and mating success in the wood tiger moth. Proc. R. Soc. B Biol. Sci. 279, 257-265. doi: 10.1098/rspb.201 1.0880

Nokelainen, O., Lindstedt, C., and Mappes, J. (2013). Environment-mediated morph-linked immune and life-history responses in the aposematic wood tiger moth. J. Anim. Ecol. 82, 653-662. doi: 10.1111/1365-2656.12037

Nokelainen, O., Valkonen, J., Lindstedt, C., and Mappes, J. (2014). Changes in predator community structure shifts the efficacy of two warning signals in Arctiid moths. J. Anim. Ecol. 83, 598-605. doi: 10.1111/1365-2656. 12169

Noonan, B. P., and Comeault, A. A. (2009). The role of predator selection on polymorphic aposematic poison frogs. Biol. Lett. 5, 51-54. doi: 10.1098/rsbl.2008.0586

O’Donald, P., and Majerus, M. E. N. (1984). Polymorphism of melanic ladybirds maintained by frequency-dependent sexual selection. Biol. J. Linn. Soc. 23, 101-111. doi: 10.1111/j.1095-8312.1984.tb00131.x

Ojala, K., Julkunen-Tiito, R., Lindstrom, L., and Mappes, J. (2005). Diet affects the immune defence and life-history traits of an Arctiid moth Parasemia plantaginis. Evol. Ecol. Res. 7, 1153-1170.

Oliver, J. C., Robertson, K. A., and Monteiro, A. (2009). Accommodating natural and sexual selection in butterfly wing pattern evolution. Proc. R. Soc. B Biol. Sci. 276, 2369-2375. doi: 10.1098/rspb.2009.0182

Osawa, N., and Nishida, T. (1992). Seasonal-variation in elytral color polymorphism in Harmonia axyridis (the ladybird beetle) - the role of nonrandom mating. Heredity 69, 297-307. doi: 10.1038/hdy.1992.129

Ozel, L. D., and Stynoski, J. L. (2011). Differences in escape behavior between a cryptic and an aposematic litter frog. J. Herpetol. 45, 395-398. doi: 10.1670/10-249.1

Parri, S., Alatalo, R. V., Kotiaho, J., and Mappes, J. (1997). Female choice for male drumming in the wolf spider Hygrolycosa rubrofasciata. Anim. Behav. 53, 305-312. doi: 10.1006/anbe.1996.0371

Partan, S., and Marler, P. (1999). Communication goes multimodal. Science 283, 1272-1273. doi: $10.1126 /$ science.283.5406.1272

Partan, S. R., and Marler, P. (2005). Issues in the classification of multimodal communication signals. Am. Nat. 166, 231-245. doi: 10.1086/431246 
Pasteels, J. M., and Rowellrahier, M. (1991). Proximate and ultimate causes for host plant influence on chemical defense of leaf beetles (Coleoptera, Chrysomelidae). Entomol. Gen. 15, 227-235. doi: 10.1127/entom.gen/15/1991/227

Peck, D. C. (2000). Reflex bleeding in froghoppers (Homoptera : Cercopidae): variation in behavior and taxonomic distribution. Ann. Entomol. Soc. Am. 93, 1186-1194. doi: 10.1603/0013-8746(2000)093[1186:RBIFHC]2.0.CO;2

Penney, H. D., Hassall, C., Skevington, J. H., Lamborn, B., and Sherratt, T. N. (2014). The relationship between morphological and behavioral mimicry in hover flies (Diptera: Syrphidae). Am. Nat. 183, 281-289. doi: 10.1086/674612

Pinheiro, C. E. G. (1996). Palatability and escaping ability in neotropical butterflies: tests with wild kingbirds (Tyrannus melancholicus, Tyrannidae). Biol. J. Linn. Soc. 59, 351-365. doi: 10.1111/j.1095-8312.1996.tb01471.x

Poulton, E. B. (1890). The Colours of Animals: Their Meaning and Use. London: Kegan Paul, Trench, Trubner.

Preissler, K., and Pröhl, H. (2017). The effects of background coloration and dark spots on the risk of predation in poison frog models. Evol. Ecol. 31, 683-694. doi: 10.1007/s10682-017-9903-6

Pröhl, H., and Hödl, W. (1999). Parental investment, potential reproductive rates, and mating system in the strawberry dart-poison frog, Dendrobates pumilio. Behav. Ecol. Sociobiol. 46, 215-220. doi: 10.1007/s002650050612

Pröhl, H., and Ostrowski, T. (2011). Behavioural elements reflect phenotypic colour divergence in a poison frog. Evol. Ecol. 25, 993-1015. doi: 10.1007/s10682-010-9455-5

Pröhl, H., Willink, B., and Hauswaldt, S. (2013). Geographic variation in sexual signals and behaviour in two species of poison frogs. Evol. Ecol. Res. 15, 667-687.

Prokopova, M., Vesely, P., Fuchs, R., and Zrzavy, J. (2010). The role of size and colour pattern in protection of developmental stages of the red firebug (Pyrrhocoris apterus) against avian predators. Biol. J. Linn. Soc. 100, 890-898. doi: 10.1111/j.1095-8312.2010.01463.x

Qvarnström, A., Rudh, A., Edstrom, T., Odeen, A., Lovlie, H., and Tullberg, B. S. (2014). Coarse dark patterning functionally constrains adaptive shifts from aposematism to crypsis in strawberry poison frogs. Evolution 68, 2793-2803. doi: 10.1111/evo.12487

Ratcliffe, J. M., and Nydam, M. L. (2008). Multimodal warning signals for a multiple predator world. Nature 455, 96-U59. doi: 10.1038/nature07087

Renoult, J. P., Kelber, A., and Schaefer, H. M. (2017). Colour spaces in ecology and evolutionary biology. Biol. Rev. 92, 292-315. doi: 10.1111/brv.12230

Reudler, J. H., Lindstedt, C., Pakkanen, H., Lehtinen, I., and Mappes, J. (2015). Costs and benefits of plant allelochemicals in herbivore diet in a multi enemy world. Oecologia 179, 1147-1158. doi: 10.1007/s00442-015-3425-0

Reynolds, R. G., and Fitzpatrick, B. M. (2007). Assortative mating in poisondart frogs based on an ecologically important trait. Evolution 61, 2253-2259. doi: $10.1111 / j .1558-5646.2007 .00174 . x$

Rice, W. R., and Hostert, E. E. (2017). Laboratory experiments on speciation: what have we learned in 40 years? Evolution 47, 1637-1653. doi: 10.1111/j.1558-5646.1993.tb01257.x

Robertson, K. A., and Monteiro, A. (2005). Female Bicyclus anynana butterflies choose males on the basis of their dorsal UV-reflective eyespot pupils. Proc. $R$. Soc. B Biol. Sci. 272:1541. doi: 10.1098/rspb.2005.3142

Rojas, B. (2012). The Apparent Paradox of Colour Variation in Aposematic Poison Frogs PhD (unpublished). Ph.D. Dissertation, Deakin University.

Rojas, B., Burdfield-Steel, E., Pakkanen, H., Suisto, K., Maczka, M., Schulz, S., et al. (2017). How to fight multiple enemies: target-specific chemical defences in an aposematic moth. Proc. R. Soc. B Biol. Sci. 284:20171424. doi: 10.1098/rspb.2017.1424

Rojas, B., and Endler, J. A. (2013). Sexual dimorphism and intra-populational colour pattern variation in the aposematic frog Dendrobates tinctorius. Evol. Ecol. 27, 739-753. doi: 10.1007/s10682-013-9640-4

Rojas, B., Gordon, S. P., and Mappes, J. (2015a). Frequency-dependent flight activity in the colour polymorphic wood tiger moth. Curr. Zool. 61, 765-772. doi: $10.1093 /$ czoolo/61.4.765

Rojas, B., Rautiala, P., and Mappes, J. (2014). Differential detectability of polymorphic warning signals under varying light environments. Behav. Process. 109, 164-172. doi: 10.1016/j.beproc.2014.08.014

Rojas, B., Valkonen, J. K., and Nokelainen, O. (2015b). Aposematism. Curr. Biol. 25, R350-R351. doi: 10.1016/j.cub.2015.02.015
Rönkä, K., De Pasqual, C., Mappes, J., Gordon, S., and Rojas, B. (2018a). Colour alone matters: no predator generalization among morphs of an aposematic moth. Anim. Behav. 135, 153-163. doi: 10.1016/j.anbehav.2017.11.015

Rönkä, K., Mappes, J., Kaila, L., and Wahlberg, N. (2016). Putting Parasemia in its phylogenetic place: a molecular analysis of the subtribe Arctiina (Lepidoptera). Syst. Entomol. 41, 844-853. doi: 10.1111/syen.12194

Rönkä, K., Mappes, J., Kivi,ö, R., Salokannas, J., Michalis, C., and Rojas, B. (2018b). Can multiple-model mimicry explain warning signal polymorphism in the wood tiger moth, Arctia plantaginis (Lepidoptera: Erebidae)? Biol. J. Linn. Soc. 124, 237-260. doi: 10.1093/biolinnean/bly042

Roper, T. J. (1994). Conspicuousness of prey retards reversal of learned avoidance. Oikos 69, 115-118. doi: 10.2307/3545290

Roper, T. J., and Redston, S. (1987). Conspicuousness of distasteful prey affects the strength and durability of one-trial avoidance learning. Anim. Behav. 35, 739-747. doi: 10.1016/S0003-3472(87)80110-0

Roque-Albelo, L., Schroeder, F. C., Conner, W. E., Bezzerides, A., Hoebeke, E. R., Meinwald, J., et al. (2002). Chemical defense and aposematism: the case of Utetheisa galapagensis. Chemoecology 12, 153-157. doi: 10.1007/s00012-002-8341-6

Rothschild, M., Aplin, R. T., Cockrum, P. A., Edgar, J. A., Fairweather, P., and Lees, R. (1979). Pyrrolizidine alkaloids in arctiid moths (Lep.) with a discussion on host plant relationships and the role of these secondary plant substances in the Arctiidae. Biol. J. Linn. Soc. 12, 305-326. doi: 10.1111/j.1095-8312.1979.tb00062.x

Rothschild, M., Moore, B. P., and Brown, W. V. (1984). Pyrazines as warning odour components in the Monarch butterfly, Danaus plexippus, and in moths of the genera Zygaena and Amata (Lepidoptera). Biol. J. Linn. Soc. 23, 375-380. doi: 10.1111/j.1095-8312.1984.tb00153.x

Rowe, C. (1999). Receiver psychology and the evolution of multicomponent signals. Anim. Behav. 58, 921-931. doi: 10.1006/anbe.1999. 1242

Rowe, C., and Guilford, T. (1999). The evolution of multimodal warning displays. Evol. Ecol. 13, 655-671. doi: 10.1023/A:1011021630244

Rowe, C., and Halpin, C. (2013). Why are warning displays multimodal? Behav. Ecol. Sociobiol. 67, 1425-1439. doi: 10.1007/s00265-013-1515-8

Rudh, A., Breed, M. F., and Qvarnstrom, A. (2013). Does aggression and explorative behaviour decrease with lost warning coloration? Biol. J. Linn. Soc. 108, 116-126. doi: 10.1111/j.1095-8312.2012.02006.x

Rudh, A., Rogell, B., Hastad, O., and Qvarnstrom, A. (2011). Rapid population divergence linked with co-variation between coloration and sexual display in strawberry poison frogs. Evolution 65, 1271-1282. doi: $10.1111 / \mathrm{j} .1558-5646.2010 .01210 . x$

Ruxton, G. D., Sherratt, T. N., and Speed, M. P. (2004). Avoiding Attack: The Evolutionary Ecology of Crypsis, Warning Signals and Mimicry. Oxford: Oxford University Press.

Ryan, M. J., Tuttle, M. D., and Rand, A. S. (1982). Bat predation and sexual advertisement in a Neotropical anuran. Am. Nat. 119, 136-139. doi: $10.1086 / 283899$

Salazar, C., Baxter, S. W., Pardo-Diaz, C., Wu, G., Surridge, A., Linares, M., et al. (2010). Genetic evidence for hybrid trait speciation in Heliconius butterflies. PLoS Genet. 6:e1000930. doi: 10.1371/journal.pgen.1000930

Santos, J. C., Baquero, M., Barrio-Amorós, C., Coloma, L. A., Erdtmann, L. K., Lima, A. P., et al. (2014). Aposematism increases acoustic diversification and speciation in poison frogs. Proc. R. Soc. B Biol. Sci. 281:20141761. doi: 10.1098/rspb.2014.1761

Santos, J. C., Coloma, L. A., and Cannatella, D. C. (2003). Multiple, recurring origins of aposematism and diet specialization in poison frogs. Proc. Natl. Acad. Sci. U.S.A. 100, 12792-12797. doi: 10.1073/pnas.21335 21100

Santos, J. C., Tarvin, R. D., and O'Connell, L. A. (2016). "A review of chemical defense in poison frogs (dendrobatidae): ecology, pharmacokinetics, and autoresistance," in Chemical Signals in Vertebrates 13, eds B. Schulte, T. Goodwin, and M. Ferkin (Springer), 305-337.

Saporito, R. A., Donnelly, M. A., Spande, T. F., and Garraffo, H. M. (2012). A review of chemical ecology in poison frogs. Chemoecology 22, 159-168. doi: 10.1007/s00049-011-0088-0

Saporito, R. A., Zuercher, R., Roberts, M., Gerow, K. G., and Donnelly, M. A. (2007). Experimental evidence for aposematism in the dendrobatid 
poison frog Oophaga pumilio. Copeia 2007, 1006-1011. doi: 10.1643/00458511(2007)7[1006:EEFAIT]2.0.CO;2

Sarto I Monteys, V., Quero, C., Santa-Cruz, M. C., Rosell, G., and Guerrero, A. (2016). Sexual communication in day-flying Lepidoptera with special reference to castniids or 'butterfly-moths'. Bull. Entomol. Res. 106, 421-431. doi: $10.1017 /$ S0007485316000158

Schultz, T. D. (2001). Tiger beetle defenses revisited: Alternative defense strategies and colorations of two neotropical tiger beetles, Odontocheila nicaraguensis Bates and Pseudoxycheila tasalis Bates (Carabidae : Cicindelinae). Coleopt. Bull. 55, 153-163. doi: 10.1649/0010-065X(2001)055[0153:TBDRAD]2.0.CO;2

Schultz, T. D., and Puchalski, J. (2001). Chemical defenses in the tiger beetle Pseudoxycheila tarsalis Bates (Carabidae : Cicindelinae). Coleopt. Bull. 55, 164-166. doi: 10.1649/0010-065X(2001)055[0164:CDITTB]2.0.CO;2

Servedio, M. (2009). The role of linkage disequilibrium in the evolution of premating isolation. Heredity 102, 51. doi: 10.1038/hdy.2008.98

Seybold, S. J., Quilici, D. R., Tillman, J. A., Vanderwel, D., Wood, D. L., and Blomquist, G. J. (1995). De novo biosynthesis of the aggregation pheromone components ipsenol and ipsdienol by the pine bark beetles Ips paraconfusus Lanier and Ips pini (Say) (Coleoptera: Scolytidae). Proc. Natl. Acad. Sci. U.S.A. 92:8393. doi: 10.1073/pnas.92.18.8393

Sharma Manmohan, D., Hunt, J., and Hosken David, J. (2011). Antagonistic responses to natural and sexual selection and the sex-specific evolution of cuticular hydrocarbons in Drosophila simulans. Evolution 66, 665-677. doi: $10.1111 / \mathrm{j} .1558-5646.2011 .01468 . x$

Shine, R. (1989). Ecological causes for the evolution of sexual dimorphism - a review of the evidence. Q. Rev. Biol. 64, 419-461. doi: 10.1086/416458

Siddall, E. C., and Marples, N. M. (2011). Hear no evil: the effect of auditory warning signals on avian innate avoidance, learned avoidance and memory. Curr. Zool. 57, 197-207. doi: 10.1093/czoolo/57.2.197

Siddiqi, A., Cronin, T. W., Loew, E. R., Vorobyev, M., and Summers, K. (2004). Interspecific and intraspecific views of color signals in the strawberry poison frog Dendrobates pumilio. J. Exp. Biol. 207, 2471-2485. doi: 10.1242/jeb.01047

Speed, M. P., and Ruxton, G. D. (2005). Aposematism: what should our starting point be? Proc. R. Soc. B Biol. Sci. 272, 431-438. doi: 10.1098/rspb.2004.2968

Srygley, R. B. (1999). Locomotor mimicry in Heliconius butterflies: contrast analyses of flight morphology and kinematics. Philos. Trans. R. Soc. B Biol. Sci. 354, 203-214. doi: 10.1098/rstb.1999.0372

Stelzer, R. J., Raine, N. E., Schmitt, K. D., and Chittka, L. (2010). Effects of aposematic coloration on predation risk in bumblebees? A comparison between differently coloured populations, with consideration of the ultraviolet. J. Zool. 282, 75-83. doi: 10.1111/j.1469-7998.2010.00709.x

Stevens, M., and Ruxton, G. D. (2012). Linking the evolution and form of warning coloration in nature. Philos. Trans. R. Soc. B Biol. Sci. 279, 417-426. doi: 10.1098/rspb.2011.1932

Stuart, Y. E., Dappen, N., and Losin, N. (2012). Inferring predator behavior from attack rates on prey-replicas that differ in conspicuousness. PLoS ONE 7:e48497. doi: 10.1371/journal.pone.0048497

Su, S. Y., Lim, M., and Kunte, K. (2015). Prey from the eyes of predators: color discriminability of aposematic and mimetic butterflies from an avian visual perspective. Evolution 69, 2985-2994. doi: 10.1111/evo.12800

Summers, K. (1987). Reproductive strategies in the green poison-dart frog, Dendrobates auratus. Am. Zool. 27:A28.

Summers, K., and Clough, M. E. (2001). The evolution of coloration and toxicity in the poison frog family (Dendrobatidae). Proc. Natl. Acad. Sci. U.S.A. 98, 6227-6232. doi: 10.1073/pnas.101134898

Summers, K., Symula, R., Clough, M., and Cronin, T. (1999). Visual mate choice in poison frogs. Proc. R. Soc. Lond. Ser. B Biol. Sci. 266, 2141-2145. doi: 10.1098/rspb.1999.0900

Svadová, K. H., Exnerová, A., Kopecková, M., and Stys, P. (2013). How do predators learn to recognize a mimetic complex: experiments with naive great tits and aposematic Heteroptera. Ethology 119, 814-830. doi: 10.1111/eth. 12121

Sword, G. A., Simpson, S. J., El Hadi, O. T. M., and Wilps, H. (2000). Densitydependent aposematism in the desert locust. Proc. R. Soc. Lond. Ser. B Biol. Sci. 267, 63-68. doi: 10.1098/rspb.2000.0967

Tabadkani, S. M., and Nozari, J. (2014). Relaxed predation hinders development of anti-predator behaviors in an aposematic beetle. Entomol. Exp. Appl. 153, 199-206. doi: 10.1111/eea.12241
Teal, P., Tumlinson, J., McLaughlin, J., Heath, R., and Rush, R. (1984). (Z)-11Hexadecen-1-OL: a behavioral modifying chemical present in the pheromone gland of female Heliothis zea (Lepidoptera: Noctuidae). Can. Entomol. 116, 777-779. doi: 10.4039/Ent116777-5

Traut, W., Sahara, K., and Marec, F. (2007). Sex chromosomes and sex determination in Lepidoptera. Sexual Dev. 1, 332-346. doi: 10.1159/000111765

Troscianko, J., and Stevens, M. (2015). Image calibration and analysis toolbox a free software suite for objectively measuring reflectance, colour and pattern. Methods Ecol. Evol. 6, 1320-1331. doi: 10.1111/2041-210X.12439

Tullrot, A. (1994). The evolution of unpalatability and warning coloration in soft-bodied marine invertebrates. Evolution 48, 925-928. doi: 10.1111/j.1558-5646.1994.tb01374.x

Tullrot, A., and Sundberg, P. (1991). The conspicuous nudibranch Polycera quadrilineata - aposematic coloration and individual selection. Anim. Behav. 41, 175-176. doi: 10.1016/S0003-3472(05)80513-5

Tuttle, M. D., and Ryan, M. J. (1981). Bat predation and the evolution of frog vocalizations in the neotropics. Science 214, 677-678. doi: $10.1126 /$ science. 214.4521 .677

Ueno, H., Sato, Y., and Tsuchida, K. (1998). Colour-associated mating success in a polymorphic Ladybird Beetle, Harmonia axyridis. Funct. Ecol. 12, 757-761. doi: 10.1046/j.1365-2435.1998.00245.x

Valkonen, J. K., Nokelainen, O., Niskanen, M., Kilpimaa, J., Bjorklund, M., and Mappes, J. (2012). Variation in predator species abundance can cause variable selection pressure on warning signaling prey. Ecol. Evol. 2, 1971-1976. doi: $10.1002 /$ ece 3.315

Vencl, F. V., Ottens, K., Dixon, M. M., Candler, S., Bernal, X. E., Estrada, C., et al. (2016). Pyrazine emission by a tropical firefly: an example of chemical aposematism? Biotropica 48, 645-655. doi: 10.1111/btp.12336

Vesely, P., Vesela, S., Fuchs, R., and Zrzavy, J. (2006). Are gregarious redblack shieldbugs, Graphosoma lineatum (Hemiptera : Pentatomidae), really aposematic? An experimental approach. Evol. Ecol. Res. 8, 881-890.

Vidal-Cordero, J. M., Moreno-Rueda, G., Lopez-Orta, A., Marfil-Daza, C., RosSantaella, J. L., and Ortiz-Sanchez, F. J. (2012). Brighter-colored paper wasps (Polistes dominula) have larger poison glands. Front. Zool. 9:20. doi: 10.1186/1742-9994-9-20

Vorobyev, M., and Osorio, D. (1998). Receptor noise as a determinant of colour thresholds. Proc. R. Soc. B Biol. Sci. 265, 351-358. doi: 10.1098/rspb.1998.0302

Wang, I. J., and Shaffer, H. B. (2008). Rapid color evolution in an aposematic species: a phylogenetic analysis of color variation in the strikingly polymorphic strawberry poison-dart frog Evolution 62, 2742-2759. doi: $10.1111 / \mathrm{j} .1558-5646.2008 .00507 . \mathrm{x}$

Wang, I. J., and Summers, K. (2010). Genetic structure is correlated with phenotypic divergence rather than geographic isolation in the highly polymorphic strawberry poison-dart frog. Mol. Ecol. 19, 447-458. doi: 10.1111/j.1365-294X.2009.04465.x

Weller, S. J., Jacobson, N. L., and Conner, W. E. (1999). The evolution of chemical defences and mating systems in tiger moths (Lepidoptera: Arctiidae). Biol. J. Linn. Soc. 68, 557-578. doi: 10.1111/j.1095-8312.1999.tb01 188.x

Willink, B., Brenes-Mora, E., Bolanos, F., and Prohl, H. (2013). Not everything is black and white: color and behavioral variation reveal a continuum between cryptic and aposematic strategies in a polymorphic poison frog. Evolution 67, 2783-2794. doi: 10.1111/evo.12153

Willink, B., Garcia-Rodriguez, A., Bolanos, F., and Prohl, H. (2014). The interplay between multiple predators and prey colour divergence. Biol. J. Linn. Soc. 113, 580-589. doi: 10.1111/bij.12355

Winters, A. E., Green, N. F., Wilson, N. G., How, M. J., Garson, M. J., Marshall, N. J., et al. (2017). Stabilizing selection on individual pattern elements of aposematic signals. Proc. R. Soc. B Biol. Sci. 284:20170926. doi: $10.1098 /$ rspb.2017.0926

Winters, A. E., White, A. M., Dewi, A. S., Mudianta, I. W., Wilson, N. G., Forster, L. C., et al. (2018). Distribution of defensive metabolites in nudibranch molluscs. J. Chem. Ecol. 44, 384-396. doi: 10.1007/s10886-018-0941-5

Wuster, W., Allum, C. S. E., Bjargardottir, I. B., Bailey, K. L., Dawson, K. J., Guenioui, J., et al. (2004). Do aposematism and Batesian mimicry require bright colours? A test, using European viper markings. Proc. R. Soc. B Biol. Sci. 271, 2495-2499. doi: 10.1098/rspb.2004.2894 
Yang, Y., Richards-Zawacki, C. L., Devar, A., and Dugas, M. B. (2016). Poison frog color morphs express assortative mate preferences in allopatry but not sympatry. Evolution 70, 2778-2788. doi: 10.1111/evo. 13079

Yoshimura, Y., and Kasuya, E. (2013). Odorous and non-fatal skin secretion of adult wrinkled frog (Rana rugosa) is effective in avoiding predation by snakes. PLOS ONE 8:e81280. doi: 10.1371/journal.pone.00 81280

Zagrobelny, M., Bak, S., Rasmussen, A. V., Jørgensen, B., Naumann, C. M., and Lindberg Møller, B. (2004). Cyanogenic glucosides and plant-insect interactions. Phytochemistry 65, 293-306. doi: $10.1016 /$ j.phytochem.2003.10.016

Zuk, M., and Kolluru, G. R. (1998). Exploitation of sexual signals by predators and parasitoids. Q. Rev. Biol. 73, 415-438. doi: 10.1086/420412
Zylinski, S., and Osorio, D. (2013). Visual contrast and color in rapid learning of novel patterns by chicks. J. Exp. Biol. 216, 4184. doi: 10.1242/jeb.085001

Conflict of Interest Statement: The authors declare that the research was conducted in the absence of any commercial or financial relationships that could be construed as a potential conflict of interest.

Copyright (C) 2018 Rojas, Burdfield-Steel, De Pasqual, Gordon, Hernández, Mappes, Nokelainen, Rönkä and Lindstedt. This is an open-access article distributed under the terms of the Creative Commons Attribution License (CC BY). The use, distribution or reproduction in other forums is permitted, provided the original author(s) and the copyright owner(s) are credited and that the original publication in this journal is cited, in accordance with accepted academic practice. No use, distribution or reproduction is permitted which does not comply with these terms. 